\title{
Modeling the global fishmeal and fish oil markets
}

\author{
C. Mullon ${ }^{1, *}$, J.-F. Mittaine ${ }^{2}$, O. Thébaud ${ }^{3}$, G. Péron ${ }^{3}$, G. Merino ${ }^{4}, M$. \\ Barange $^{4}$
}

\footnotetext{
${ }^{1}$ Unité de recherche Ecosystèmes marins exploités. Avenue Jean Monnet. 34200, Sète. France

${ }^{2}$ Conservatoire National des Arts et Métiers. Paris. France

${ }^{3}$ IFREMER, UMR AMURE, Département d'économie maritime, BP 70, F-29280, Plouzané, France

${ }^{4}$ Plymouth Marine Laboratory. Prospect Place Plymouth, PL1 3, UK
}

*: Corresponding author : C. Mullon, email address : Christian.Mullon@ird.fr

\begin{abstract}
:
To explore the drivers of change in the complex system relating small pelagic fisheries and fishmeal/fish oil markets, to identify the interactions between these drivers and their overall impacts, we propose a bio-economic model, coupling the ecological and the economic dynamics of these global commodities. The model enables an analysis of the consequences of both global and local changes in the environment of production systems. Through sensitivity analysis of specific input parameters, we evaluate the robustness of the overall system to such changes and show that local responses of production systems and markets cannot be considered in isolation from the set of interactions at global level.
\end{abstract}

Keywords: Bio-economic modeling $\bullet$ networks economics $\bullet$ small pelagic fisheries $\bullet$ fishmeal $\bullet$ fish oil

\section{Introduction}

Small pelagic fisheries, anchovies, sardines, etc., represent about a third of the global wild marine catch. They constitute the first step of an industrial process that transforms fresh, bony fish of small size but generally rich in protein and high in fat content into two high quality products, meal and oil, both products being mostly used as key ingredients in specific animal feeds (Cf. appendix A). The link between the fisheries and the end-users goes through a series of steps that constitute an industrial and marketing chain covering the entire world as generally producing 
regions (mainly South America) are quite far away from the major consuming sectors (mainly Asia and Western Europe). Therefore, the industrial chain includes various steps such as processing, trading, logistics, transportation (fig. 1).

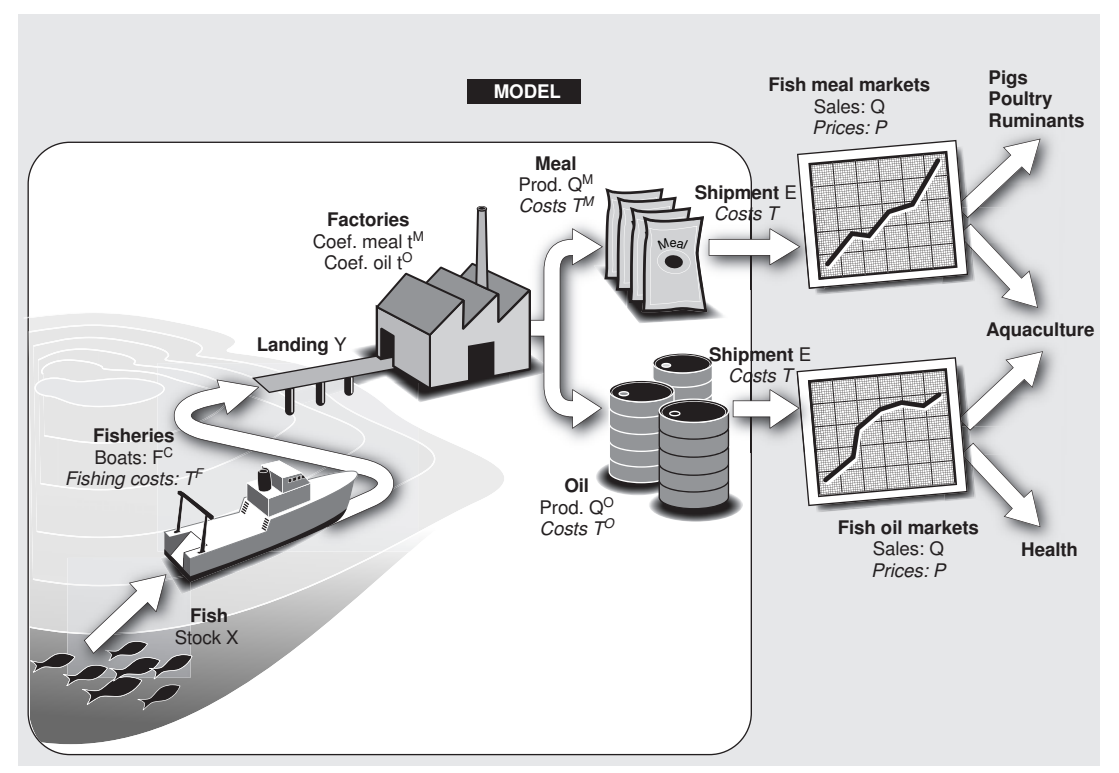

FIGURE 1. Fish-meal and fish-oil markets and their supply chain

A major feature of the system relating small pelagic fisheries and fishmeal / fish oil markets is the complex combination of a highly variable natural renewable resource, a modern, geographically diverse industrial processing structure, a worldwide commodity-based price sensitive market and highly selective and fully industrialized end-users, many of them located far away from the product source. Very little is known on how stocks of small pelagic fisheries are affected by external factors such as climate change (Hannesson et al. (2006), Lehodey et al. (2006)), increasing harvesting costs due to the growth in fuel oil prices, or demand growth on specific markets. Given the globalized nature of the markets on which fishmeal and fish oil are traded and the growing integration of large scale fisheries ventures worldwide (Garcia and Grainger (2005), Hannesson et al. (2006)), the consequences of such changes must be considered in the light of interactions between the different production systems throughout the world, which may either dampen or inflate the impacts of perturbations felt locally.

To illustrate and quantify the stakes of which this complex system is the subject, we have developed a specific supply-demand model. Such a model provides a framework to address issues regarding (1) the vulnerability of the small pelagic fisheries to both climate variability and change in the economic context in which fishmeal and fish oil are produced, particularly the increase in fuel oil prices and (2) the supply of fishmeal and fish oil markets in the context of a developing aquaculture demand from emerging economies and global price trends in food commodities. The goal of our model is to provide a tool to better understand the fish oil / fishmeal 
production/consumption system and more generally to ascertain what are the main processes of a worldwide market for a marine renewable resource.

The aim of fisheries simulation models (Grant et al. (1981), Isakson et al. (1982), Sparre and Willman (1993), Ulrich et al. (2002), Mardle and Pascoe (2002), Lleonart et al. (2003), Merino et al. (2007)) is to facilitate the analysis of the consequences and risks, both economic and ecological, associated to different scenarios regarding the co-evolution of fish stocks and fisheries subject to changing economic, environmental and management contexts. The model presented here differs mainly by the spatial scale to which the analysis is applied. Most of these models do not internalize different stocks' production into a global framework but into local markets, assuming these markets to be influenced by imports. Contrastively, this one aims to aggregate different small pelagic stocks exploitation into a single bio-economic model with two commodities on a global market. The model considers several stocks gathering small pelagic species, but no ecological interactions between them. It is the transformed production of landings from different stocks, which interacts with other stocks in a common global market.

In this model, world's small pelagic stocks are characterized by means of surplus production models (Schaefer (1954)) where the fishing mortality term depends on local management decisions. Producers vary their fishing capacity according to the profit they derive from fishing. Profits for each producer result from both the volume of production traded, the associated costs in terms of fishing, transformation and shipment, and the price at which production is sold. Price dynamics take into account the existence of financial externalities, with fishmeal and oil quantities sold on a common market determining each producer's sale price. The responses of producers in terms of investment in capacity, and in terms of fishing, determine the evolution of the exploited populations and the economic outcome of the activity.

The structure of the model developed to represent this system is detailed in Section 1. Section 2 presents the data used to calibrate the model and the scenarios tested. Section 3 presents the simulation results for these scenarios. Section 4 discusses these results and concludes.

\section{Structure And Equations of the MOdel}

Modeling choices. The system of small pelagic fisheries and fishmeal or fish oil markets is represented as an oligopolistic system with two commodities. This results in a network with a bi-layered structure with, on the side of supply, the set of production systems, from fish to fishmeal and fish oil, on the side of demand, the set of fish product markets, and the economic exchanges between them (fig. 2).

To represent the dynamics of the system, we have build a model that couples (1) the economic equilibrium between production systems selling on fish products markets, and (2) deterministic evolution rules for production systems and fish products markets. Thus the model considers two time scales.

On a short time scale (less than one year), each fishery in competition with other fisheries, determine how much to fish, where to sell according to the status of the fish stocks, to the intensity of demand; choices are computed as the equilibrium of the previous competition; to compute this equilibrium, we use the formalism of network economics (Nagurney (1993)), which provides a common framework to problems issued from spatial economics Samuelson (1952), game theory, migration 


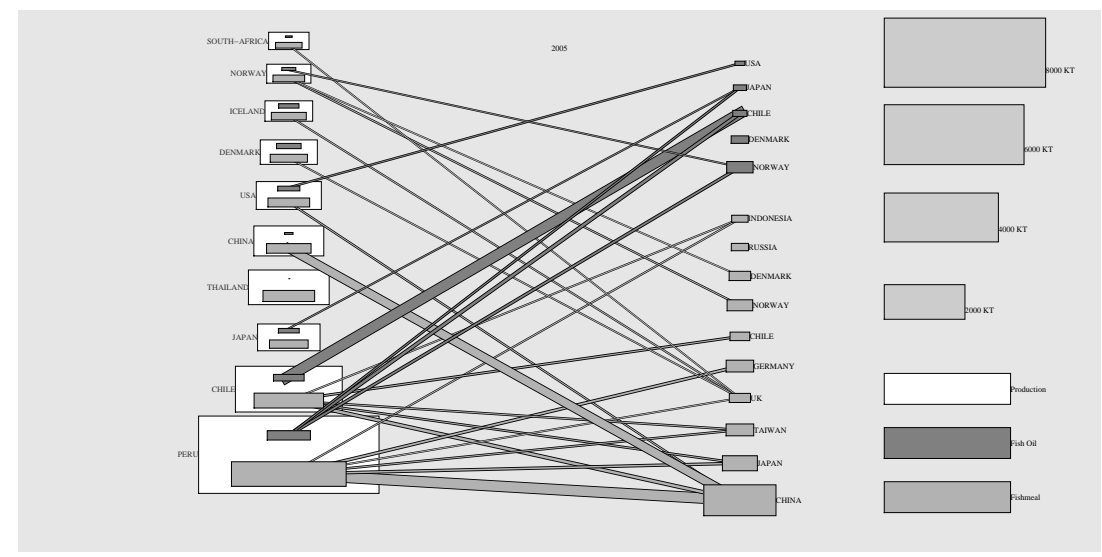

FIGURE 2. Global network structure of the system: are represented, on the left part, fish catches, fish-meal and fish-oil production, on the right art, the fish-meal and fish-oil consumption; in the middle part, the arrows represent shipments. Size of boxes is proportional to volumes. Size of links is proportional to shipments. Remark the importance of Peru as a producer, of China as a consumer. These flows represent more than $70 \%$ of total world trade of fihsmeal and fish oil.

or traffic studies. It reveals being more adapted to the analysis of supply chains than conventional general equilibrium approach.

On a longer time scale, influenced by the choices of fisheries and the resulting incomes, fish stocks, fishing capacities and market demand all evolve in an exogenous manner.

All notations and equations of the model are resumed in tables 1 and 2 .

Entities. According to a preliminary exploratory data analysis, entities of the model have been chosen as several national production systems and several national fish product markets. A production system is therefore a national structure that groups dedicated fleet and associated transformation factories. The model simplifies the players by using only the production and consumption systems that capture the majority of the trade. Peru, Chile, Japan, Thailand, China, USA, Denmark, Iceland, Norway, Morocco and South Africa are the main production systems, representing more than $70 \%$ of the world production of small pelagic fish. Fishmeal markets in China, Japan, Taiwan, UK, Germany, Chile, Norway, Denmark, Russia, Indonesia, while fish oil markets in Norway, Denmark, Chile, Japan, USA, representing more than $80 \%$ of the world fish product consumption are the consumption systems. This is according to the present state of the small pelagic and fishmeal and fish oil markets. It must be underlined that this system is characterized by the fast emergence of producers, such as Vietnam since the mid 1990s and Ecuador over the last decade, and recent consumers, such as Greece. To avoid overcomplexity, we have chosen not to consider these sudden structural changes in the present version of the model. 
Summary of model notations and equations. Notations and equations of the model are summarized in tables 1 and 2 .

TABLE 1. Notations of the model. Top: characteristics of the competitive equilibrium. Bottom: characteristics of the dynamical system.

\begin{tabular}{|c|c|c|c|}
\hline Notation & Entities & Unit & Type \\
\hline$s$ & Production systems & & \\
\hline$k$ & Fish products markets & & \\
\hline$M$ & Set of fish-meal markets & & \\
\hline$O$ & Set of fish-oil markets & & \\
\hline$F_{s}$ & Fishing capacity of $s$ & $m^{3}$ & From dynamical model \\
\hline$U_{s}$ & Used fishing capacity (Effort) of $s$ & $m^{3}$ & Variable \\
\hline$X_{s}$ & Fish stock of $s$ & ton & From dynamical model \\
\hline$q_{s}$ & Fish catchability of $s$ & $\operatorname{ton}^{-1} m^{-3}$ & Fixed \\
\hline$Y_{s}$ & Landing of $s$ & ton & Variable \\
\hline$Y_{s}^{q u o t a}$ & TAC for $s$ & ton & According to scenario \\
\hline$Y_{s}^{\max }$ & Maximum landing of $s$ & ton & Variable \\
\hline$c_{s}$ & Fishing costs per yield & Dollar / ton of fish & Constant \\
\hline$e_{s}$ & Fishing costs per unit of effective effort & Dollar $/ \mathrm{m}^{3}$ & According to scenario \\
\hline$T_{s}^{F}$ & Fishing costs for $s$ & Dollar/ton of fish & Variable \\
\hline$T_{s}^{M}$ & Meal production costs for $s$ & Dollar / ton of meal & Constant \\
\hline$T_{s}^{O}$ & Oil production costs for $s$ & Dollar / ton of oil & Constant \\
\hline$T_{s k}^{s}$ & Shipment costs from $s$ to $k$ & Dollar ton of product & According to scenario \\
\hline$E_{s k}$ & Shipment from $s$ to $k$ & ton & Variable \\
\hline$\tau_{m}$ & Technical production coefficient for meal & ton of fish / ton of meal & Constant \\
\hline$\tau_{o}$ & Technical production coefficient for oil & ton of fish / ton of oil & Constant \\
\hline$Y_{s}$ & $\begin{array}{ll}\text { Fishing capacity } \\
\end{array}$ & $m^{3}$ & From equilibrium model \\
\hline$Y_{S}$ & Landings & $t$ & From equilibrium model \\
\hline$E_{s k}$ & Shipments & $t$ & From equilibrium model \\
\hline$P_{k}^{s k}$ & Prices & Dollars & From equilibrium model \\
\hline$C_{s k}$ & Costs & Dollar & From equilibrium model \\
\hline$C_{s}$ & Carrying capacity & $t$ & According to scenario \\
\hline$r_{s}$ & Renewal rate & & According to scenario \\
\hline$i_{s}$ & Investment rate & $\%$ & According to scenario \\
\hline$j_{s}$ & Amortization rate & $\%$ & According to scenario \\
\hline$K_{s}$ & Capital costs & Dollar & According to scenario \\
\hline$v_{s}$ & Price of fishing unit & $t$ & Constant \\
\hline$t_{s}$ & Capital remuneration rate & $t$ & According to scenario \\
\hline
\end{tabular}

\section{Notations.}

Characterization of shipments. For all shipments between production system $s$ and market $k$, we denote the shipped quantity $E_{s k}$. In the next paragraphs, we show how a given combination of shipments $E=\left(E_{s k}\right)$ determines all other characteristics of the system, mainly costs and prices. This is the key point of the approach.

Characterization of markets. We use the symbol $M$ for meal markets, $O$ for oil markets. For all markets $k$, we denote $P_{k}$ the unitary prices, $Q_{k}$ the traded volume.

Characterization of production systems. Concerning the biological state of production system $s$, we denote $X_{s}$ the stock, $C_{s}$ the carrying capacity, $r_{s}$ the renewal rate. To characterize the economic state of a production system $s$, we consider that every vessel has a capacity defined as the volume $\left(\mathrm{m}^{3}\right)$ of maximum catchable fish quantity per fishing trip (Ward et al. (1999), Pascoe et al. (1999)). Then the fishing capacity of a production system is the sum of the capacities of all its fishing vessels. We denote $F_{s}$ the fishing capacity of production system $s$. If $v_{s}$ denotes the value of an unit $\left(\mathrm{m}^{3}\right)$ of fishing capacity, then the capital of production system $s$ is $K_{s}=v_{s} F_{s}$.

According to context, a production system may decide to use only a part of its fishing capacity; we denote $U_{s}$ the used fishing capacity, i.e. the effective effort; 
TABLE 2. Equations of the model. Top: characteristics of the competitive equilibrium. Bottom: characteristics of the dynamical system.

\begin{tabular}{|c|c|}
\hline Equilbrium & Equations \\
\hline Conservation equations & $\begin{array}{l}Q_{k}=\sum_{s} E_{s k} \\
Q_{s}^{M}=\sum_{k \in M} E_{s k} \\
Q_{s}^{O}=\sum_{k \in O} E_{s k}\end{array}$ \\
\hline Maximum landing & $Y_{s}^{\max }=\operatorname{Min}\left(q_{s} F_{s} X_{s}, Y_{s}^{q u o t a}\right)$ \\
\hline Production constraints & $\tau_{m} Q_{s}^{M} \leq Y_{s}^{\max }, \tau_{o} Q_{s}^{O} \leq Y_{s}^{\max }$ \\
\hline Yield equation & $Y_{s}=\operatorname{Max}\left(Q_{s}^{M} \tau_{m}, Q_{o}^{M} \tau_{o}\right)$ \\
\hline Used fishing capacity & $U_{s}=Y_{s} /\left(q_{s} X_{s}\right)$ \\
\hline $\begin{array}{l}\text { Fishing costs as a function } \\
\text { of stock }\end{array}$ & $T_{s}^{F}=c_{s}+e_{s} /\left(q_{s} X_{s}\right)$ \\
\hline $\begin{array}{l}\text { Fishing, production and } \\
\text { shipment costs }\end{array}$ & $\begin{array}{l}C_{s k}=T_{s}^{M}+T_{s}^{F} Y_{s} \tau^{M} /\left(\tau^{M} Q_{s}^{M}+\tau^{O} Q_{s}^{O}\right)+T_{s k} \text { for } s \in M \\
C_{s k}=T_{s}^{O}+T_{s}^{F} Y_{s} \tau^{O} /\left(\tau^{M} Q_{s}^{M}+\tau^{O} Q_{s}^{O}\right)+T_{s k} \text { for } s \in O .\end{array}$ \\
\hline Prices & $P_{k}=a_{k}-b_{k} Q_{k}$ \\
\hline Functional relationship & $E=\left(E_{s k}\right) \rightarrow R=\left(R_{s k}\right)=\left(C_{s k}-P_{k}\right)$ \\
\hline Complementarity equation & $\begin{array}{l}E^{*}=\left(E_{s k}^{*}\right) \text { with associated } R^{*}=\left(R_{s k}^{*}\right) \text { is an equilibrium if } \\
\text { for all } s \text { there exists } \lambda_{s}^{M} \geq 0, \lambda_{s}^{O} \geq 0 \text { such that for all } k: \\
\qquad \begin{array}{l}\text { (1) for } k \in M, E_{s k}^{*}>0 \Rightarrow R_{s k}^{*}+\lambda_{s}^{M}=0 \\
\text { and } E_{s k}^{*}=0 \Rightarrow R_{s k}^{*}+\lambda_{s}^{M} \geq 0 \\
\text { (2) } Q_{s}^{* M}<Y_{s}^{\max } / \tau_{m} \Rightarrow \lambda_{s}^{M}=0 \\
\text { (3) for } k \in O, E_{s k}^{*}>0 \Rightarrow R_{s k}^{*}+\lambda_{s}^{O}=0 \\
\text { and } E_{s k}^{*}=0 \Rightarrow R_{s k}^{*}+\lambda_{s}^{O} \geq 0 \\
\text { (4) } Q_{s}^{* O}<Y_{s}^{\max } / \tau_{o} \Rightarrow \lambda_{s}^{O}=0\end{array}\end{array}$ \\
\hline Dynamics & Equations \\
\hline Stock evolution & $X_{s}(t+1)=r_{s} X_{s}(t)\left(1-X_{s}(t) / C_{s}\right)-Y_{s}(t)$ \\
\hline $\begin{array}{l}\text { Profit definition } \\
\text { Capital definition } \\
\text { Capital costs definition } \\
\text { Net profit definition } \\
\text { Fishing capacity evolution }\end{array}$ & $\begin{array}{l}I_{s}=\sum_{k} E_{s k}\left(P_{k}-C_{s k}\right) \\
K_{s}=v_{s} F_{s} \\
t_{s} K_{s} \\
I_{s}-t_{s} K_{s} \\
F_{s}(t+1)=\left(1-i_{s} t_{s}-j_{s}\right) F_{s}(t)+\left(i_{s} / v_{s}\right) I_{s}(t)\end{array}$ \\
\hline
\end{tabular}

overcapacity is a major issue of small pelagic fisheries Fréon et al. (2008). Our definition of fishing capacity is related to the concept of a frontier production function (Coelli et al. (2005)).

We denote the fishing costs $T_{s}^{F}$, the production costs $T_{s}^{M}, T_{s}^{O}$ and production volumes $Q_{s}^{M}$ and $Q_{s}^{O}$.

\section{Economic equilibrium.}

Balance equations. The traded volume is the sum of all shipped quantities:

$$
Q_{k}=\sum_{s} E_{s k}
$$

We assume that there is no storage, which is what is observed during last years, thus that production equals sales:

$$
Q_{s}^{M}=\sum_{k \in M} E_{s k} \quad, \quad Q_{s}^{O}=\sum_{k \in O} E_{s k}
$$

Getting yield and effort. We note $\tau_{m}, \tau_{o}$ the technical transformation coefficients for meal and oil (the volume of fish needed to produce one ton of the commodity). We get yield assuming that there are no losses:

$$
Y_{s}=\operatorname{Max}\left(Q_{s}^{M} \tau_{m}, Q_{o}^{M} \tau_{o}\right)
$$

Using a conventional relationship between yield $Y_{s}$, stock, effective effort and catchability: $Y_{s}=q_{s} X_{s} U_{s}$, we deduce the effective effort: 


$$
U_{s}=Y_{s} /\left(q_{s} X_{s}\right)
$$

Costs. For a product shipped on a path from a production system $s$ to a market $k$, unitary $\operatorname{costs} C_{s k}$ are the sum of (1) costs due to the fishing process, (2) production costs assumed to be constant: $T_{s}^{M}$ for meal, $T_{s}^{O}$ for oil, (3) shipment costs assumed to be constant: $T_{s k}$.

Total fishing costs for a production system $s$ are partly due due to effective effort, partly due to the amount of fish caught. We assume a linear relationship: $c_{s} Y_{s}+e_{s} U_{s}$ where coefficient $c_{s}$ is the cost per ton of fish caught and $e_{s}$ is the cost of using an unit of fishing capacity; as we have assumed that $Y_{s}=q_{s} U_{s} X_{s}$, we get the unitary fishing costs: $T_{s}^{F}=c_{s}+e_{s} /\left(q_{s} X_{s}\right)$.

Fishmeal and fish oil are two commodities extracted from the same product; one is an auxiliary product of the others; today there are countries producing meal without oil because lacking of a market; the inverse situation is possible in a next future. To compute the equilibrium and the choice of a producer to favor one commodity or the other, according to their selling prices and their production costs, we propose to allocate fishing costs to fishmeal or fish oil production according to ratios $\tau^{M} Q_{s}^{M} /\left(\tau^{M} Q_{s}^{M}+\tau^{O} Q_{s}^{O}\right)$ and $\tau^{O} Q_{s}^{O} /\left(\tau^{M} Q_{s}^{M}+\tau^{O} Q_{s}^{O}\right)$; with this simplification, if a commodity is not produced, it does not cost; if both commodities are produced at their maximum value $\left(\tau^{M} Q_{s}^{M}=\tau^{O} Q_{s}^{O}=Y_{s}\right)$, corresponding ratios are $1 / 2$; this simplification is justified by the fact that how production systems decide between meal and oil is not a crucial feature of the global system.

After some elementary algebraic manipulation, we get the expression of the unitary production and shipments costs on a path:

$$
\begin{aligned}
& C_{s k}=T_{s}^{F} Y_{s} \tau^{M} /\left(\tau^{M} Q_{s}^{M}+\tau^{O} Q_{s}^{O}\right)+T_{s}^{M}+T_{s k} \text { for } k \in M \\
& C_{s k}=T_{s}^{F} Y_{s} \tau^{O} /\left(\tau^{M} Q_{s}^{M}+\tau^{O} Q_{s}^{O}\right)+T_{s}^{O}+T_{s k} \text { for } k \in O
\end{aligned}
$$

Inverse demand function. We base our representation of the short-term formation of first-sale prices on standard studies of this in fisheries (Garcia (2006), Ioannidis and Whitmarsh (1987), Gordon and Hanneson (1996), Nielsen (1999), Anderson $(2003 ; 1980))$. We assume that local producers are price takers, i.e. that they have no individual control on the overall supply of fish. For any given level of demand for their production, the overall volumes sold on the market will however define the levels of prices which will paid to individual producers in the different production systems. We have chosen to use a linear functional relationship relating prices to quantities:

$$
P_{k}=a_{k}-b_{k} Q_{k} .
$$

Functional relationship. We have successively shown how shipments determine sales (equation 1), how shipments determine commodities production (equation 2), how commodities production determines yield (equation 3), how commodities production and yield determine costs (equations 5 and 6 )), how sales determine market prices (equation 7 ). Thus, to a combination of shipments $E=\left(E_{s k}\right)$, we may associate the combination $R=\left(R_{s k}\right)$ where $R_{s k}=C_{s k}-P_{k}$ is the difference, for an unit of commodity, between production and transportation costs and market 
price. Using previous results and definitions, it is obvious that this a functional relationship $E \rightarrow R$. Let's remark that, due to the shape of equations 5 and 6 , this relationship is non linear

Constraints equations. Not every combination of shipments is possible. There are several types of constraints affecting production. Firstly, catches are limited, either by a technical constraint, related to the fishing capacity: $Y_{s} \leq q_{s} F_{s} X_{s}$ where $q_{s}$ is the catchability of fish in the ecosystem, or an administrative constraint, such as total allowable catches: $Y_{s} \leq Y_{s}^{q u o t a}$. If there is no catch limitation, we put $Y_{s}^{q u o t a}=\infty$. We have:

$$
Y_{s} \leq \operatorname{Min}\left(q_{s} F_{s} X_{s}, Y_{s}^{q u o t a}\right)
$$

Secondly, there are technical constraints related to the meal or oil processing:

$$
\tau_{m} Q_{s}^{M} \leq Y_{s}^{\max } \quad \text { and } \quad \tau_{o} Q_{s}^{O} \leq Y_{s}^{\max }
$$

We denote $\mathcal{H}$ the set of combinations of shipments $E=\left(E_{s k}\right)$ such that $E_{s k} \geq 0$ and $Y_{s} \leq Y_{s}^{\max }$ where $Y_{s}$ is determined by equations 2 and 3 .

Competitive equilibrium. A production system $s$ increases its production $Q_{s}^{M}$ and $Q_{s}^{O}$ and its shipments $E_{s k}$ until either (1) they are not profitable $R_{s k}=0$, or (2) a production threshold has been reached $Q_{s}^{M}=\tau_{m} Y_{s}^{\max }$ or $Q_{s}^{O}=\tau_{o} Y_{s}^{\max }$. This encompasses the following mathematical definition of market equilibrium.

Definition A feasible combination $E^{*}=\left(E_{s k}^{*}\right) \in \mathcal{H}$ with associated $R^{*}=\left(R_{s k}^{*}\right)$ is an equilibrium if for all production system $s$ there exists coefficients $\lambda_{s}^{M} \geq 0$, $\lambda_{s}^{O} \geq 0$ such that for all markets $k$ two "complementarity" conditions hold:

(1) for a meal market $k \in M, R_{s k}^{*}+\lambda_{s}^{M} \geq 0$, and $E_{s k}^{*}>0$ implies $R_{s k}^{*}+\lambda_{s}^{M}=0$ and $E_{s k}^{*}=0$ implies $R_{s k}^{*}+\lambda_{s}^{M} \geq 0$; moreover $\lambda_{s}^{M}=0$ when $\tau_{m} Q_{s}^{* M}<$ $Y_{s}^{\max }$

(2) for an oil market $k \in O, R_{s k}^{*}+\lambda_{s}^{O} \geq 0$ and $E_{s k}^{*}>0$ implies $F_{s k}^{*}+\lambda_{s}^{O}=0$ and $E_{s k}^{*}=0$ implies $R_{s k}^{*}+\lambda_{s}^{O} \geq 0$; moreover $\lambda_{s}^{O}=0$ when $\tau_{o} Q_{s}^{* O}<Y_{s}^{\max }$.

In this definition, $\lambda_{s}^{M}$ (resp. $\lambda_{s}^{O}$ ) is the excess cost (shadow price) of production system $s$ when producing fish-meal (resp. fish-oil). This definition means that, for a producer, advantages to sell on a market are the same for all effective markets; if this was not the case, the producer would have an advantage to sell more to the most advantageous of markets.

To analyze and compute the equilibrium set of this system, we use the formalism of network economics (Nagurney (1993)), which allows reformulating a supplydemand system in a general framework. Based on the "variational inequality theory", which is a generalization of convex programming, this approach determines in which conditions the equilibrium of an economic network exists and is computable.

We consider shipments $E_{s k}$ satisfying $E_{s k} \geq 0$; we compute $Y_{s}$ and $Q_{k}$ according to balance equations. We denote $\mathcal{H}$ the set of shipments such that $Y_{s} \leq Y_{s}^{\max }$. Then we have the following fundamental theorem:

Theorem 2.1. A shipment combination $\left(E_{s k}^{*}\right) \in \mathcal{H}$ is an equilibrium as defined in paragraph 2 if and only if it satisfies the variational inequality 


$$
\sum_{s k} R_{s k}^{*}\left(E_{s k}-E_{s k}^{*}\right) \geq 0
$$

for all shipments $E=\left(E_{s k}\right) \in \mathcal{H}$.

We give the proof in appendix B. Then, we use a basic result of variational inequality theory.

Theorem 2.2. There exists an equilibrium shipment

Proof is application of Brouwer's fixed point theorem and is due to the facts that (1) $\mathcal{H}$ is a convex and compact subset of $\mathbb{R}^{n}$ and (2) $F$ is continuous from $\mathbb{R}^{n}$ to $\mathbb{R}^{n}$ (Nagurney (1993)).

According to these results we may compute then equilibrium using one of the different algorithms defined in (Nagurney (1993)) and (Facchinei and Pang (2003)). We use the modified descent algorithm (Zhu and Marcotte (1993)), which reveals, in our context, being converging to a solution of the variational inequality.

Dynamics. The dynamics of the system are implemented according to the following recurrence mechanism. At time $t$, using (1) demand functions and (2) production costs and shipping costs functions, we solve the equilibrium equations, getting flows $E_{s k}(t)$, production $Q_{s}^{M}(t)$ and $Q_{s}^{O}(t)$, traded quantities $Q_{k}$, prices $P_{k}$ and costs $C_{s k}$. Then, between time $t$ and time $t+1$, we compute the new state of production systems: stock $X_{s}(t+1)$, and fishing capacity $F_{s}(t+1)$ and the new demand function of markets $a_{k}(t+1)$ and $b_{k}(t+1)$. This is detailed in the next paragraphs.

Investment dynamics. We assume an adaptive anticipations framework to represent investment behavior in production systems: investment at each time step is assumed to depend on anticipations regarding future profit by investors, which depend directly on the observation by them of past economic performance in a given production system. This is the background of many models representing fisheries investment behavior (Smith (1969)). We consider the special case where investors follow a myopic behavior, i.e. investment at each time step is a function of the performance observed for the production system at the previous time step. According to this assumption evolution of fishing capacity is related to investment depreciation.

A production system is characterized by fishing capacity $F_{s}$, capital $K_{s}=v_{s} F_{s}$, and profit $I_{s}=\sum_{k} E_{s k}\left(P_{k}-C_{s k}\right)$. Capital costs are $K_{s} t_{s}$ with capital remuneration rate $t_{s}$. Net profit (that is taking account of capital costs) is $I_{s}-K_{s} t_{s}$. Then a fixed proportion of net profit $i_{s}\left(I_{s}-K_{s} t_{s}\right)$ is reinvested. The number of new units of fishing capacity is $i_{s}\left(I_{s}-K_{s} t_{s}\right) / v_{s}$. Depreciation is $j_{s} F_{s}$ with depreciation rate $j_{s}$. Finally, we get:

$$
\begin{aligned}
F_{s}(t+1) & =F_{s}(t)+i_{s}\left(I_{s}(t)-K_{s}(t)\right) / v_{s}-j_{s} F_{s}(t) \\
& =\left(1-i_{s} t_{s}-j_{s}\right) F_{s}(t)+\left(i_{s} / v_{s}\right) I_{s}(t)
\end{aligned}
$$


Stock dynamics. Evolution function of stock is a conventional production function with the renewal rate $r_{s}$, and the carrying capacity $C_{s}$ :

$$
X_{s}(t+1)=r_{s} X_{s}(t)\left(1-X_{s}(t) / C_{s}\right)-Y_{s}(t)
$$

\section{InPUt AND OUtPut of THE MODEL}

Data. The model uses as input data quantitative characteristics of production systems, markets and shipping paths. Tables 3 and 4 describe the biological (renewal rate, carrying capacity, catchability, initial stock) and economical (fishing capacity, price of a fishing unit, fishing costs, transformation costs) characteristics of production systems. Table 5 describes fish product markets: average observed prices $\bar{P}_{s}$ and average observed volumes $\bar{Q}_{s}$ during 5 last years.

To build these tables, we have proceed as follows. From databases from the Food and Agriculture Organisation (FAO) and the International Fishmeal and Fish oil Organisation (IFFO), we have extracted (1) for all countries, data concerning catches $Y_{s}$, commodities (meal and oil) production $Q_{s}^{M}, Q_{s}^{O}$, commodities consumption, commodities flows $E_{s k} ;(2)$ for Peru, Chile, Norway, Denmark, Island, data concerning fishing capacity $F_{s}$ and used fishing capacity $U_{s}$, fishing costs $T_{s}^{F}$, commodities production costs $T_{s}^{M}$ and $T_{s}^{O}$; (3) data concerning observed prices $P_{k}$ and volumes $Q_{k}$ on the main fishmeal or fish oil markets. No inflation is considered in the model, which works on the basis of nominal values, as finding the right index for adjusting the different prices to real values does not seem straightforward. Although databases of the FAO go back to the 1950s, we have chosen the last five years to estimate the economical variables of the model. The advantages of this choice is that, although we do not take into account the effect of climate events such as the $1997 \mathrm{El}$ Nino event, we have a reference baseline of relatively stable catches and prices, which we may consider relevant to the development of a robust modeling framework. For production systems $s$, when not available, the mean fish stock $X_{s}$, the carrying capacity $K_{s}$, the intrinsic growth rate $r_{s}$, the catchability $q_{s}$ have been extrapolated in order to provide production stationarity: $X_{s}=K_{s} / 2$, $Y_{s}=q_{s} X_{s} U_{s}=r_{s} X_{s}\left(1-X_{s} / K_{s}\right)$.

Then, using these tables, other characteristics of the system have been obtained as follows. For production system $s$, fishing costs parameters have been estimated as $c_{s}=T_{s}^{F} / 2$ and $e_{s}=q_{s} X_{s} T_{s}^{F} / 2$. For market $k$, coefficients of the inverse demand function, $a_{k}$ and $b_{k}$, have been estimated from observations, during the 2000-2005 period, of averaged prices $\bar{P}_{k}$ and quantities $\bar{P}_{k}: a_{k}=2 \bar{P}_{k}, b_{k}=\bar{Q}_{k} / \bar{P}_{k}$ (flexibility $-d P_{k} / d Q_{k}$ is 1 when market is in averaged state $\left.\bar{P}_{k}, \bar{Q}_{k}\right)$. For path $s \rightarrow k$, shipment $\operatorname{costs} C_{s k}$ (table 6 ) have been extrapolated in order to observe a network equilibrium, that is: if $E_{s k}>0$ then $C_{s k}-P_{k}=0$.

Building scenarios. Scenario building consists of making explicit assumptions about the underlying processes, setting the corresponding values to model parameters, and then interpret the results of the resultant simulation model. Concerning the production systems, we observe the dynamics of stocks, yield, fishing capacity, effective effort, profit, and concerning the markets, we observe volumes of exchanges and prices of commodities. Model parameters (endogenous variables) are given in table 7 with their default values, and how they affect a running simulation. 
Impact of climate change. Scenarios about the impact of climate change (cf. table 7 , part 1) consist of changing the values of production functions parameters: $r_{s}(t)$, $C_{s}(t)$. We usually consider the following scenarios (1) Climate change results in a uniform increase (or decrease) of renewal rates, assuming that it affects fish recruitment processes; (2) Climate change results in a uniform increase (or decrease) of carrying capacity, assuming that it affects the overall productivity of ecosystems. (3) Climate change results in a localized increase (or decrease) of carrying capacity, assuming that it affects the productivity of ecosystems in a different manner according to their latitudinal location.

Economic globalization. Building a scenario in terms of economic globalization consists of changing production and transportation costs (cf. table 7, part 2). We usually consider the following scenarios (1) Economic globalization affects shipment costs, for example through the increasing use of containers, or the increase of fuel prices, (2) Economic globalization results in increasing demand for forage fish

TABLE 3. Characteristics of producers. The meaning of symbols is as follows. $r$ is is the renewal rate, $K$ the carrying capacity, $X$ the initial stock. $K$ and $X$ values have been set in order to represent the past estimates of the stock, with an optimistic hypothesis of a maximum sustainable state; then other parameters have been estimated in order to fit with past observed production (2000-2005 period).

\begin{tabular}{|r|r|r|r|r|}
\hline & $\begin{array}{r}\mathrm{r} \\
\text { (no unit) }\end{array}$ & $\begin{array}{r}\mathrm{K} \\
\text { (tons) }\end{array}$ & $\begin{array}{r}\text { Catchability } \\
\text { (ton per } \mathrm{m}^{3} \text { ) }\end{array}$ & $\begin{array}{r}\mathrm{X} \\
\text { (tons) }\end{array}$ \\
\hline CHILE & 1.000 & 10682000 & 13.9 & 5341000 \\
CHINA & 0.503 & 18952000 & 14.2 & 9476000 \\
DENMARK & 0.999 & 4098000 & 19.8 & 2049000 \\
ICELAND & 0.741 & 3703000 & 19.1 & 1851000 \\
JAPAN & 0.994 & 4018000 & 19.1 & 2009000 \\
MOROCCO & 0.976 & 1211000 & 35.9 & 605000 \\
NORWAY & 0.841 & 5002000 & 19.1 & 2501000 \\
PERU & 1.000 & 26306000 & 10.5 & 13153000 \\
SOUTH AFRICA & 0.558 & 4113000 & 23.9 & 2056000 \\
THAILAND & 0.070 & 9697000 & 24.8 & 4848000 \\
USA & 0.667 & 4153000 & 20.1 & 2076000 \\
VIETNAM & 0.593 & 1811000 & 34.6 & 905000 \\
\hline
\end{tabular}

TABLE 4. Characteristics of producers. FC is the fishing capacity, PFC the selling price of an unit of fishing capacity $\left(\right.$ per $\left.m^{3}\right)$, Fish the fish yield, Meal the meal production, Oil the oil production, FC the fishing costs, PCMeal the meal transformation costs, PCOil the oil transformation costs. These values have been estimated from IFFO data.

\begin{tabular}{|c|c|c|c|c|c|c|c|c|}
\hline & $\begin{array}{r}\mathrm{FC} \\
\left(m^{3}\right)\end{array}$ & $\begin{array}{r}\text { P FC \$ } \\
\left(\text { per } m^{3}\right)\end{array}$ & $\begin{array}{r}\text { Fish } \\
\text { (tons) }\end{array}$ & $\begin{array}{r}\text { Meal } \\
\text { (tons) }\end{array}$ & $\begin{array}{r}\text { Oil } \\
\text { (tons) }\end{array}$ & $\begin{array}{l}\text { FC \$ (per } \\
\text { (ton fish) }\end{array}$ & $\begin{array}{r}\text { PC Meal } \$ \\
\text { (per ton) }\end{array}$ & $\begin{array}{l}\text { PC Oil } \$ \\
\text { (per ton) }\end{array}$ \\
\hline CHILE & 50000 & 9600 & 3209000 & 817000 & 157000 & 63 & 120 & 200 \\
\hline CHINA & 40000 & 2200 & 3000000 & 790000 & 0 & 70 & 110 & 160 \\
\hline DENMARK & 25000 & 3600 & 981000 & 326000 & 105000 & 91 & 180 & 230 \\
\hline ICELAND & 25000 & 5000 & 1100000 & 248000 & 80000 & 64 & 250 & 300 \\
\hline JAPAN & 25000 & 4000 & 1111500 & 250000 & 64000 & 62 & 200 & 300 \\
\hline MOROCCO & 10000 & 1600 & 135000 & 2700 & 0 & 50 & 80 & 160 \\
\hline NORWAY & 20000 & 5000 & 1118000 & 219000 & 55000 & 84 & 250 & 300 \\
\hline PERU & 150000 & 2000 & 8200000 & 1807000 & 321000 & 47 & 100 & 200 \\
\hline SOUTH AFRICA & 10000 & 2400 & 524000 & 118000 & 4000 & 81 & 120 & 160 \\
\hline THAILAND & 10000 & 1600 & 466000 & 397000 & 0 & 40 & 80 & 140 \\
\hline USA & 18000 & 4400 & 930400 & 258000 & 92000 & 73 & 220 & 280 \\
\hline VIETNAM & 7000 & 1400 & 153000 & 50000 & 0 & 50 & 70 & 100 \\
\hline
\end{tabular}


TABLE 5. Volumes and prices on different fish products markets (average on the 2000-2005 period). From IFFO.

\begin{tabular}{|r|r|r|}
\hline & $\begin{array}{r}\text { price } \\
\text { (\$ per ton) }\end{array}$ & $\begin{array}{r}\text { volume } \\
\text { (tons) }\end{array}$ \\
\hline MEAL & & \\
\hline CANADA & 560 & 77000 \\
CHILE & 600 & 258000 \\
CHINA & 614 & 1900000 \\
DENMARK & 663 & 196000 \\
ICELAND & 900 & 60000 \\
INDONESIA & 579 & 88000 \\
JAPAN & 626 & 637000 \\
MOROCCO & 892 & 56000 \\
NORWAY & 688 & 268000 \\
PERU & 516 & 248000 \\
SOUTH AFRICA & 511 & 100000 \\
TAIWAN & 619 & 268000 \\
UK & 880 & 229000 \\
USA & 800 & 183000 \\
VIETNAM & 535 & 46000 \\
\hline OIL & & \\
\hline CHILE & 650 & 207000 \\
DENMARK & 607 & 22000 \\
JAPAN & 568 & 118000 \\
NORWAY & 770 & 231000 \\
PERU & 544 & 40000 \\
USA & 1234 & 33000 \\
\hline
\end{tabular}

TABLE 6. Shipping costs between production systems and fish-meal or fish-oil markets. Shipping paths are determined from IFFO data. Shipping costs are related to distance but are adjusted to production costs in order the system converge towards an equilibrium with positive shipments on these paths.

\begin{tabular}{|c|c|c|c|c|c|c|c|c|c|c|c|c|}
\hline & $\mathrm{CHI}$ & CHI & DEN & ICE & JAP & MOR & NOR & PER & S.A & THA & USA & VIE \\
\hline MEAL & & & & & & & & & & & & \\
\hline CANADA & & . & & - & & & . & . & & . & 75 & \\
\hline CHILE & 52 & . & & . & & & . & & & . & & \\
\hline CHINA & 288 & 56 & & . & & 233 & & 285 & & . & 190 & 73 \\
\hline DENMARK & & . & & & & & 52 & & 239 & . & & . \\
\hline ICELAND & & . & & 39 & & & . & & & & & . \\
\hline INDONESIA & 288 & . & & & & . & . & 289 & & 75 & & . \\
\hline JAPAN & 285 & . & 147 & . & 62 & & . & 277 & 257 & . & 156 & . \\
\hline MOROCCO & & . & & . & & 62 & . & & & . & & . \\
\hline PERU & & . & & . & & & & 77 & & . & & . \\
\hline NORWAY & & . & & . & & & 61 & & & . & & \\
\hline SOUTH AFRICA & & . & & . & & & . & & 64 & . & & . \\
\hline TAIWAN & 282 & . & 179 & & & & & 277 & 252 & . & 174 & . \\
\hline UK & . & . & 68 & 72 & & 91 & 84 & 237 & 224 & . & & . \\
\hline USA & . & . & & 146 & & & . & 161 & & . & 98 & \\
\hline VIETNAM & . & . & & . & & & . & & & . & & 42 \\
\hline OIL & & & & & & & & & & & & \\
\hline CHILE & 46 & . & & . & & & & 83 & & . & & \\
\hline DENMARK & . & . & 46 & . & & & 71 & & & . & & . \\
\hline JAPAN & . & . & & . & 48 & & & 264 & & & & \\
\hline NORWAY & . & . & & . & & & 47 & 246 & & & & . \\
\hline PERU & . & . & & . & & & . & 77 & & . & & \\
\hline USA & . & . & & 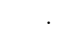 & & & & & & & 114 & \\
\hline
\end{tabular}

products, (3) Economic globalization results in a localized (e.g. China) increase of demand for forage fish products, (4) Economic globalization affects capital behavior: more and more of profit is affected to capital remuneration, (5) Economic globalization affects investment behavior, (6) Economic globalization and competition result in technological change and increasing of catchability.

Sensitivity analysis. The objectives of a sensitivity analysis are to observe changes of the dynamics resulting from different values of one parameter. Practically, we perform sensitivity analysis of the behavior of the model in the following way: (1) 
TABLE 7. Parameters for scenarios (a) on the impact of climate change, top, (b) on the impact of economic globalization

\begin{tabular}{|c|c|c|c|}
\hline Climate change & & & \\
\hline Parameter & & $V_{0}$ & Effect \\
\hline $\begin{array}{l}\text { Carrying } \\
\text { changes }\end{array}$ & $a$ & 0 & Every year, carrying capacities $C_{s}$ are multiplied by $(1+a)$ \\
\hline Renewal rate changes & $b$ & 0 & Every year, renewal rates $r_{s}$ are multiplied by $(1+b)$ \\
\hline $\begin{array}{l}\text { Latitudinal climate } \\
\text { changes }\end{array}$ & $l$ & 0 & $\begin{array}{l}\text { Every year, carrying capacity of a production system } s \text { at latitude } \\
l a t_{s}, C_{s} \text {, is multiplied by }\left(1+l\left(l a t_{s}-40\right) / 40\right)\end{array}$ \\
\hline El Nino Event & $e$ & 0 & $\begin{array}{l}\text { For year } 3 \text { and } 4 \text {, carrying capacity of a production in Peru and } \\
\text { Chile is multiplied by }(1-e)\end{array}$ \\
\hline $\begin{array}{l}\text { Economic global- } \\
\text { ization }\end{array}$ & & & \\
\hline Parameter & & $V_{0}$ & Effect \\
\hline $\begin{array}{l}\text { Demand changes (in- } \\
\text { tercept) }\end{array}$ & $c d$ & 0 & $\begin{array}{l}\text { Every year, demand parameters (intercept) } a_{k} \text { are multiplied by } \\
(1+c d)\end{array}$ \\
\hline $\begin{array}{ll}\text { Demand } & \text { changes } \\
\text { (slope) } & \end{array}$ & $c s$ & 0 & Every year, demand parameters (slope) $b_{k}$ are multiplied by $(1+c s)$ \\
\hline $\begin{array}{l}\text { Growth of fish-meal } \\
\text { markets }\end{array}$ & $g m$ & 0 & $\begin{array}{l}\text { Every year, for fish-meal markets } k \text {, demand parameters (intercept) } \\
a_{k} \text { are multiplied by }(1+g m)\end{array}$ \\
\hline $\begin{array}{l}\text { Growth of Chinese de- } \\
\text { mand }\end{array}$ & $c d$ & 0 & $\begin{array}{l}\text { Every year, on Chinese market } k \text {, demand parameters (intercept) } \\
a_{k} \text { are multiplied by }(1+c d)\end{array}$ \\
\hline $\begin{array}{l}\text { Adaptation of fishing } \\
\text { capacity }\end{array}$ & $a f$ & 0.1 & Reinvestment rate $i_{s}=a f$ \\
\hline $\begin{array}{l}\text { Capital remuneration } \\
\text { rate }\end{array}$ & $\mathrm{cr}$ & 0.1 & Capital coefficients $t_{s}=\mathrm{cr}$ \\
\hline Amortization rate & $a r$ & 0.1 & Capital coefficients $t_{s}=a r$ \\
\hline Catchability changes & $c c$ & 0 & Every year, catchability coefficients $q_{s}$ are multiplied by $(1+c c)$ \\
\hline Total allowable catch & $t a$ & 1 & Maximum of catches $Y_{s}^{\max }=t a C_{s}$ \\
\hline Fuel prices changes & $p c$ & 0 & $\begin{array}{l}\text { Every year, for all production systems } s \text {, fishing costs } C_{s} \text { are multi- } \\
\text { plied by }(1+0.8 p c) \text {, for all paths, shipping costs } C_{s k} \text { are multiplied } \\
\text { by }(1+0.2 p c)\end{array}$ \\
\hline Fishing rights & $f r$ & 0 & Added to fishing costs \\
\hline Importation taxes & it & 0 & Added to shipping costs on path ending in concerned country \\
\hline
\end{tabular}

select a "sensitive" parameter in the parameter listed in table 7, (2) set maximum and minimal values for this parameter, (3) set values for the other parameters according to some scenario whose sensitivity has to be tested, (4) set which variables of the system are to be observed, (5) run the model for 11 values of the selected parameter, regularly placed in the range (minimum, maximum).

\section{Results I : Scenarios}

Uniform increase of carrying capacity scenario. Although climate change could both increase or decrease carrying capacity (Brander (2007)), for this exercise we assume that it has a positive effect on pelagic ecosystems and that it results in a regular $10 \%$ per year increase in carrying capacity, for all production systems. We present in figure 3 the kind of results we observe for all scenarios. In this particular one, fish stocks improve and consequently yields stabilize. Profit is increasing. With increasing supply and constant demand, there are less and less "borderline" countries. The decrease of fishing costs due to greater stocks, even if limited, allows all of them to gain more and more on the global market. However, our assumption of a myopic investment behavior is the cause of overcapacity increases. There is a low decrease of prices for fishmeal, significant for fish oil; when stocks are very high, production costs are mainly due to fixed costs; this is due to the cost function: $T_{s}^{F}=c_{s}+e_{s} /\left(q_{s} X_{s}\right)$; the nature of this function implies that high values of stocks $X_{s}$ have an effect on prices which is less important than low values; this effect is higher for fish oil due to the higher transformation coefficient. 

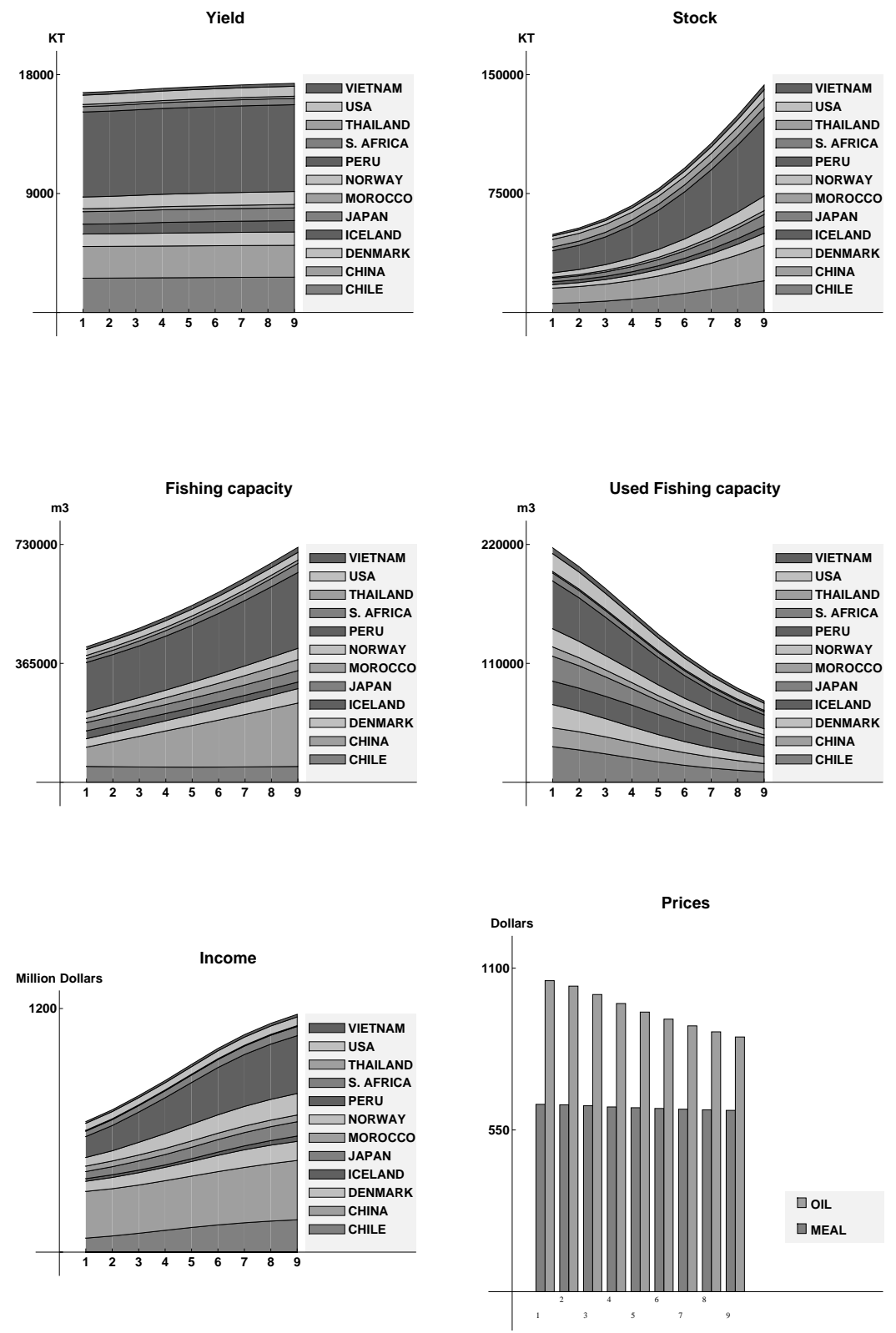

FIGURE 3. Scenario of an uniform increase of carrying capacity. Every year there is a $10 \%$ increase of carrying capacity. Are represented, for all production systems, the fish yield (KTons); the fish stock (KT); the fishing capacity $\left(\mathrm{m}^{3}\right)$; the effective effort $\left(\mathrm{m}^{3}\right)$; the profit of the fishing sector (dollars); and the mean observed prices (dollars/ton)

Increase in fuel price scenario. Second scenario is about how the system behaves when fuel prices increase by $5 \%$ per year, which is rather conservative, according to what has happened in recent years (figure 4). It has an effect both on fishing 
costs and shipping costs. At a given level of fuel prices, it is no more profitable to fish and thus boats are idled. The inefficiency of the fishery ensures that the smaller supply is not compensated by an increase in commodity price. The increase in production costs is limited, due to the necessity of taking into account fixed prices (capital costs). Profit decreases drastically in affected countries, and even though fishing capacity decreases overcapacity reaches a high level. This causes the collapse of several fisheries, (e.g. for example, that of Peru highly affected by increase of transportation costs), a decrease in global supply to under $10 \mathrm{Mt}$, which is not enough to satisfy demand. Decrease of yield results in a continued growth of stocks, underlying that collapse of fisheries are not due only to collapses of stocks. This process will continue until a level equivalent to the carrying capacity, in support of the idea that an increase of fuel prices would contribute to fisheries sustainability (Sumaila et al. (2008)). However, the collapse of fisheries would have catastrophic economic effects.

Global total allowable catches (TAC) scenario. Next scenario concerns the dynamics of the system under the assumption that catch limits are imposed for all ecosystems at a level of $5 \%$ of the estimated carrying capacity. This is a very conservative level compared to surplus production estimates (Jacobson et al. (2001)), which cannot reasonably be expected at the global level. We observe, in agreement with theory, a stabilization of stock, yield, profit and prices (cf. Supplementary material). Prices are $20 \%$ higher than in the reference scenario, insuring high profit, and therefore high investment and thus overcapacity. In general terms this is similar to present conditions observed in Peru (Fréon et al. (2008)). This scenario suggest that in China, catch limits ensure a very high profit and increase in fishing capacity. However, a global fishmeal producing fish yield of 15 MT is too small to supply the fishmeal and fish oil demand, compared to the present yield 20 MT. Effects of this low supply on the development of aquaculture have to be analyzed. Indeed, what appears from these results is the efficiency of catch limits on an ecological and partly on an economic point of view: they insure high level of stocks and high profit to fisheries, but may result in an insufficient supply for markets.

\section{Results II : Sensitivity analysis}

El Nino. This first sensitivity analysis concerns the effects of an El Nino event as resulting in anchovy biomass drop rates $0 \%, 8 \%, 16 \%, \ldots, 80 \%$ in Peru and Chile during third and fourth year of simulation. In figure 5 are plotted the resulting values of yield, stock, fishing capacity, profit and prices. The level of stock recovery after an El Nino event determines two pathways. If the stock recovers (in biological terms), quickly exploitation and markets reach a level similar to the levels preceding the El Nino event. If recovery is delayed, fishing pressure is likely to remain high during the recovering period, and both exploitation levels and markets have to stabilize at a lower level than before the event. One may consider that this is a mechanism of shifting baseline (Pauly (1995), Pinnegar and Engelhard (2008)), which on a long term endangers the global production system.

Uniform increase of demand. A second sensitivity analysis concerns the effects of a constant demand increase of $0 \%$ to $5 \%$ per year. This last yearly increase represents an increase of $62 \%$ at the end of a 10 years period. We observe (cf. 

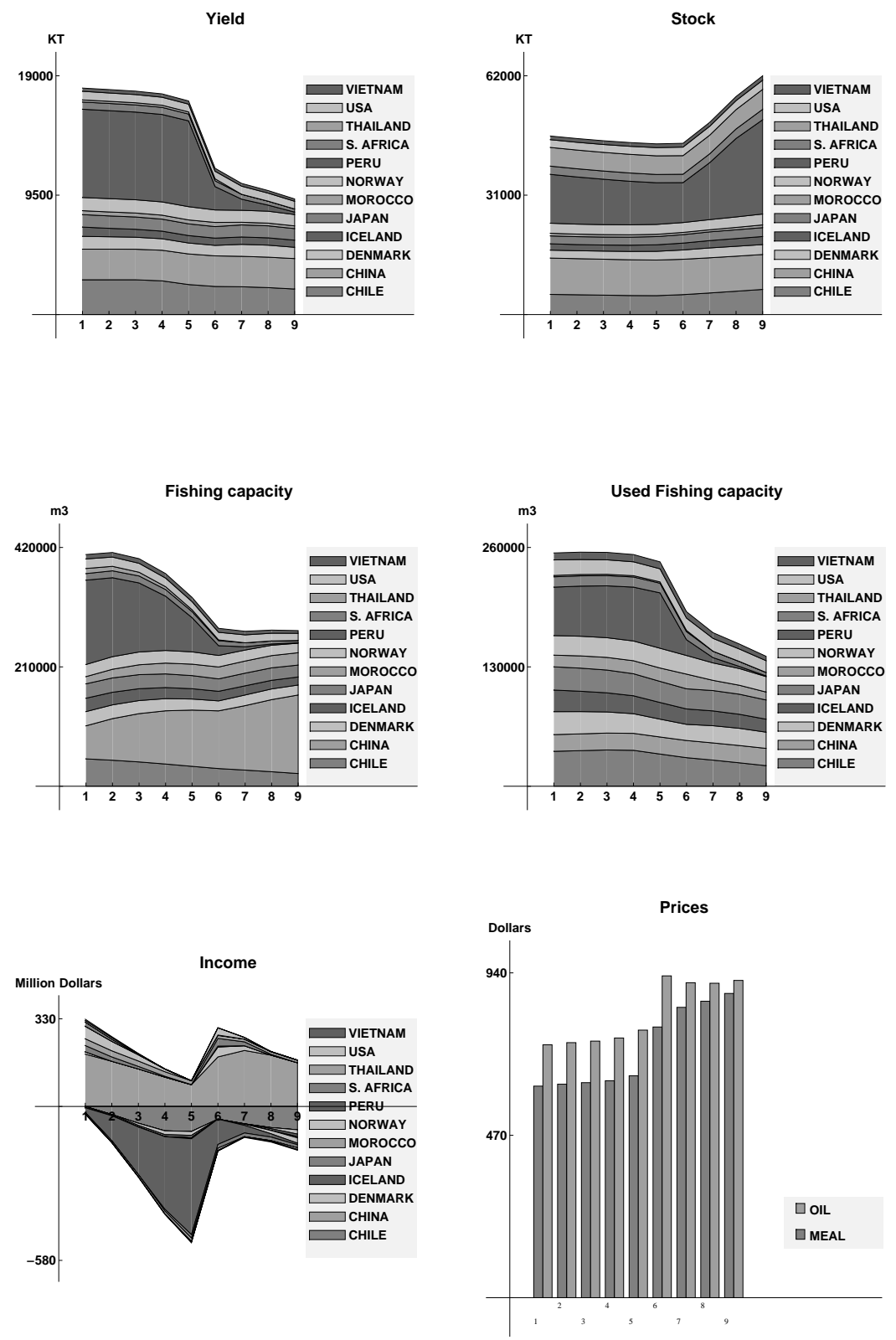

FiguRE 4. Scenario of a regular increase of fuel prices. Every year there is a $10 \%$ increase of fuel prices

Supplementary material) that the rate of demand growth has a huge impact on prices, profit, investment and overcapacity. Decrease of stocks is smooth, but at the end they reach a level at which exploitation is no more profitable. The dynamics of yield presents a plateau effect, which is a dangerous situation: observing only yield may conceal that stocks are endangered (Mullon et al. (2005)). This has to be related to the lack of concurrency on the fishmeal market, much dominated by the 

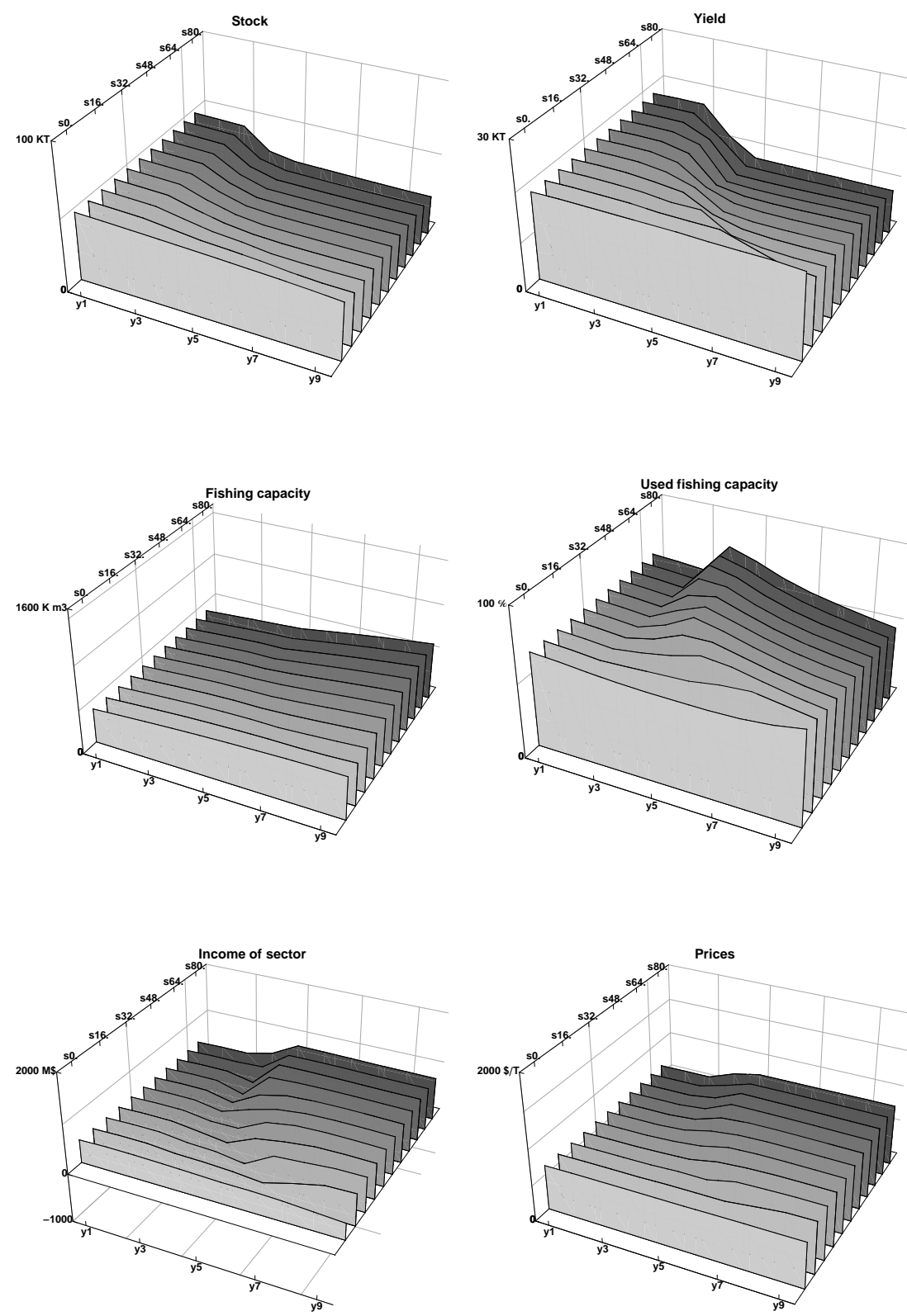

Figure 5. Sensitivity analysis: impact of El Nino events. In each graph, a slice corresponds to an intensity of El Nino: s16 to a drop of $16 \%$ of stock in Peru and Chile during year 3 and 4. A slice represents the dynamics of a characteristics of the system during years $y 1, \ldots, y 10$. 
Peruvian production system, where producers are de facto limiting their supply. With this control, they get a higher profit and, according to the myopic investment behavior, have a tendency to invest too much, whence overcapacity.

Total allowable catches (TAC). Preliminary studies (Jacobson et al. (2001)) have estimated that the average exploitation of anchovy stocks can be estimated at approximately $8.5 \%$ of carrying capacity and sardine at $5 \%$ of carrying capacity, based on their average surplus production. In this sensitivity analysis, we vary the level of TAC successively from $5 \%$ to $45 \%$ of carrying capacity. In all cases (cf. Supplementary material), we observe that a TAC limit stabilizes the stock and the profit from its exploitation. As expected, high levels of TAC result in over exploitation and price drops, while low levels of TAC result in high prices and overcapacity. There is an optimal profit value at TAC levels of around $12 \%$ of pristine biomass, with particular effects at the fishing behavior level. It appears in considering fishing capacity and effective effort graphs that at such optimal exploitation levels there is an encouragement to increase investment, increase in total (but not necessarily used) fishing capacity, with an inexorable decrease in global profit.

\section{Discussion}

Our objective was to develop a model, which would allow exploring the importance of interactions between regional fisheries, their regional and global markets and global production capital, in assessing the impacts of exogenous perturbations on local fisheries systems. The context of the analysis is a renewable resource, characterized by a highly variable supply and a strongly increasing demand for the commodities it produces. The emphasis of the analysis is on representing the full set of interactions between different production systems, and on analyzing the impacts of assumptions made regarding these interactions on the simulated dynamics.

To develop the model, we have followed a Pattern Oriented Modeling approach (Grimm et al. (2005)): the model has been designed to reproduce several identified dynamics, such as shifts, cascades or collapses, operating on both economical and ecological levels; this leads to the choices of a limited set entities and time resolution (10 years with 1-year steps); this leads to test the model on the basis of sensitivity analyzes of the dynamics to several parameters, before being used to develop scenarios of climate change, globalization, etc.

Most important modeling choices we have done are: (1) from an economical point of view, to consider the investment behavior as myopic and that landed volumes determine prices in a linear fashion, (2) from an ecological point of view, consider the system as mono specific, although it is difficult to envisage unique biological parameters for functional groups including short living and long living species, (3) from a modeling perspective, to represent the dynamics as resulting from the coupling of a market equilibrium process (annual balance between supply and demand determines trade and prices) with a dynamic deterministic process (present ecosystem state, fisheries, and trade determine next year's ecosystem state and fisheries.

Each scenarios tells us a different story, expressed as specific causality schemes. Due to the possible knowledge of all characteristics of entities during a simulation, it is possible to analyze results and conclude what mechanisms drive the systems. In every case, and for every scenario, there are ecological and economic explanations 
to the observed dynamics. Occasionally, the ecological and economic interpretation may sound paradoxical. For example, an increase of biological productivity results in decreasing profit, a decrease in stock size may result in an increasing exploitation, until a threshold value is reached, an increase of profit may result in capacity rises and thus in decreasing profit rates. Equally, there is an impact level of El Nino events beyond which the recovering slows down, which may sound a paradox for economists. Building such scenarios allows discussion in an interdisciplinary context, the main use of this model. It is important to realize, however, that due to the large number of uncontrolled exogenous variables, the capacity of this model for forecasting is limited.

If we consider the results concerning the effects of El Nino events with the ones concerning an increase of demand, we may hypothesize that there is certainly a threshold of increase of demand at which the system is not able to recover of severe El Nino events. If we consider these results with the ones concerning the implementation of TAC policies, we may hypothesize that specific regimes of TAC for Peru and Chile would ensure a better resistance of the system, and envisage its consequences about the structure of capital and profit. By this way, we derive the terms of new scenarios, of new sensitivity analysis. And we may put them at stake in the context of a global negotiation. This is the content of our present research and will detailed in a forthcoming paper.

From the many simulating experiences and sensitivity analysis we have realized, we would like to emphasize two specific conclusions.

Firstly, the global system in the last decades has been dominated by production from Peru, and an efficient TAC system there has stabilized small pelagic stocks. One could conclude that this stabilization of the dominant fishery may allow other countries to overexploit their resource, causing local collapses that may recover in the medium term without affecting the efficiency of global the system in any substantial manner. This dynamics have clearly been observed in our model simulations. However, one must underline that not all collapsed stocks have historically recovered in the medium term (e.g. Namibian sardine), and that the main weakness of the global system lies in the possibility of a climatically-driven collapse of the Peruvian stock combined with the present large overcapacity (Fréon et al. (2008)).

Secondly, the myopic investment behavior assumed in the model does provide a very simple explanation to fishing overcapacity (Fréon et al. (2008)). A TAC guaranties rents and encourages over investment. Do we fight over capacity or do we accept it just as a necessary negative effect of an ecologically-efficient management policy? Is overcapacity the result of an adaptation process to maximize profit during good periods, in anticipation of individual quotas being allocated based on present fishing capacity, while keeping options open should a drop in biological production require disinvestment? These are the kind of questions for which our modeling approach provides a mechanism and a formalism to explore.

It is important to note that this is not just a conceptual model but one where procedures for validation and calibration are considered. As a short term model, it is possible to relate model conclusions with actual events, which allows for practical validation. Our approach was based on defining reasonable values for model parameters from literature and data analysis, illustrating the functioning of the model with scenarios and sensitivity analyzes, and then interpreting the consequences as applied to the real system small pelagic fisheries and their products. This gives 
plausibility to our conclusions. For example, we underline that the importance of the increase of fuel prices on the stability of the system; we could also say that our assumptions concerning the decoupling of the fishmeal markets and the soya meal markets has been confirmed.

However, it is important to say that developing a short term model assumes some stability in its structural features, while it appears that these are evolving quickly. These elements advocate in favor of a more adaptive model, which is a real challenge for the future. As adaptations of the structure of the model, we should consider modeling the appearance or disappearance of new producers or consumers (for example, the development of the Vietnam fishmeal industry these two last years suggests that this country should be included in the model) or the changes of the connectivity of the network (for example due to the increase in the use of containers). We should also consider the potential ecological synchronies between anchovy and sardine, the substitution processes, the recycling of by-product of aquaculture, using more realistic costs functions (non linear) to represent effects of elasticities and cross elasticities, etc.

The global view of the model is proven very useful in an interdisciplinary context, making explicit messages across from ecologists to economics, reflecting on the importance of variability, of the differential renewal rates between stocks, and of carrying capacity on stock dynamics. It also allows feedback discussions from economist to ecologists on questions of elasticities, importance of price formation processes and investment behavior.

On a short term perspective, the model is adaptable to the socio-economic and political scenarios from the Intergovernmental Panel of Climate Change (Nakicenovic (2000)) and permits the quantitative evaluation of these scenarios; global change is not only described through the direct climate impacts on small pelagic populations (Chavez et al. (2003)) but through a pool of variables deciding future technological improvement trends, international cooperation or events such as substitution of fishmeal by soya meal in aquaculture. Even in the absence of an immediate crisis, frameworks such as the Millenium Assessment could be put forward to form the basis of international discussions regarding small pelagic fisheries management (Barange (2008)). This modeling approach could help to illustrate the major stakes of such discussions: the liability of the system for a global management, the identification of scales, agents, entities, levels of organization to be taken into account, the impact of factors such as the level of ecosystem variability, the evolution of the biomass, regulatory and macro-economic constraints, markets behavior, impacts of production growth.

\section{REFERENCES}

J. Alheit and M. Niquen. Regime shifts in the humboldt current ecosystem. Progress In Oceanography, 60(2-4):201-222, 2004.

J. L. Anderson. The international seafood trade. Woodhead Publishing Limited., 2003.

R. W. Anderson. Some theory of inverse demand for applied demand analysis. European Economic Review, 14:281-290, 1980.

F. Asche and S. Tveteras. On the relationship between aquaculture and reduction fisheries. Journal of Agricultural Economics, 55(2):245-265, 2004. 
M. Barange. Reconciling fisheries with conservation and constraints of climate change. American Fisheries Symposium, 2(49):977-980, 2008.

M. Barange, I. Hampton, and B.A. Roel-Payne. Trends in the abundance and distribution of anchovy and sardine on the south african continental shelf in the 1990s, deduced from acoustic surveys. S. Afr. J. Mar. Sci., 21:367-391, 1999.

K. M. Brander. Global fish production and climate change. Proceedings of the National Academy of Sciences of the United States of America, 104(50):1970919714, 2007.

F. P. Chavez, J. Ryan, S. E. Lluch-Cota, and M. C. Niquen. From anchovies to sardines and back: Multidecadal change in the pacific ocean. Science, 299(5604): 217-221, 2003.

M. A. Cisneros-Mata, M.O Nevarez-Martinez, and M. G. Hamman. The rise and the fall of the pacific sardine, sardinops sagax caeruleurs girard, in the gulf of california, mexico. Calcofi Rep. 36, CALCOFI, Instituto Nacional de la Pesca Centro Regional de Investigaciones Pesqueras (INP-CRIP) Guaymas, Sonora, 85400 Mexico, 1995.

T.J. Coelli, D.S.P. Rao, C.J. O'Donnell, and G.E. Battese. An Introduction to Efficiency and Productivity Analysis. Springer-Verlag, 2005.

J.C. Coetzee, D. Merkle, C.L. Cunnigham, N.M. Twatwa, M. Barange, and D.S. Butterworth. Updated south african hydro-acoustic surbey estimates of pelagic fish biomass: effects of target strength, signal attenuation and receiver saturation. Afr. J. Mr. Sci., 2008.

L. Deutsch, S. Graslund, C. Folke, M. Troell, M. Huitric, N. Kautsky, and L. Lebel. Feeding aquaculture growth through globalization: Exploitation of marine ecosystems for fishmeal. Global Environmental Change, 17(2):238-249, 2007.

F. Facchinei and J.-S. Pang. Finite-Dimensional Variational Inequalities and Complementary Problems, volume I and II. Springer-Verlag, New-York, 2003.

P. Fréon, M. Bouchon, C. Mullon, C. García, and C. Niquen. Interdecadal variability of anchoveta abundance and overcapacity of the fishery in peru. Progr. Oceanogr., In press, 2008.

J. G. Garcia. The Spanish Hake Market: Price, Product and Market Relationships. $\mathrm{PhD}$ thesis, Universitat de Barcelona, 2006.

S. M. Garcia and R. J. Grainger. Gloom and doom? the future of marine capture fisheries. Philosophical Transactions of the Royal Society B: Biological Sciences, 360(1453):21-46, 2005. doi: http://dx.doi.org/10.1098/rstb.2004.1580.

D. V. Gordon and R. Hanneson. On the price of the fresh and frozen cod. Marine Resource Economics, 11:223-238, 1996.

W. E. Grant, K. G. Isakson, and W. L. Griffin. A general bioeconomic simulation model for annual-crop marine fisheries. Ecol. Model., 13(3):195-219, 1981.

V. Grimm, E. Revilla, U. Berger, F. Jeltsch, W. M. Mooij, S. F. Railsback, H.-H. Thulke, J. Weiner, T. Wiegand, and DeAngelis D. L. Pattern-oriented modeling of agent-based complex systems: lessons from ecology. Science, 310:987-991, 2005.

R. Hannesson, M. Barange, and S. F. Herrick. Climate change and the economics of the world's fisheries: examples of small pelagic stocks, volume xvii. Edward Elgar, Cheltenham, UK, 2006. 
R. W. Hardy and A. G. J. Tacon. Responsible Marine Aquaculture, chapter Fish meal : historical uses, production trends and future outlook for sustainable supplies, pages 311-326. CAB International, 2002.

C. Ioannidis and D. Whitmarsh. Price formation in fisheries. Marine Policy, 2: 143-145, 1987.

K.G. Isakson, W.E. Grant, and W.L. Griffin. General bioeconomic fisheries simulation model: A detailed model documentation. Journal of International Sociological and Ecological Modeling, 4:61-85, 1982.

L. D. Jacobson, J. A.A De Oliveira, M. Barange, M. A. Cisneros-Mata, R. FélixUraga, J. R. Hunter, J. Y. Kim, Y. Matsuura, M. Niquen, C. Porteiro, B. Rothschild, R. P. Sanchez, R. Serra, A. Uriarte, and Tokio W. Surplus production, variability, and climate change in the great sardine and anchovy fisheries. Can. J. Fish. Aquat. Sci., 58(9):1891-1901, 2001.

T. Kawasaki. Recovery and collapse of the far eastern sardine. Fisheries Oceanography, 2(3-4):244-253, 1993.

D. Kristofersson and J. L. Anderson. Is there a relationship between fisheries and farming? interdependence of fisheries, animal production and aquaculture. Marine Policy, 30(6):721-725, 2006.

P. Lehodey, J. Alheit, M. Barange, T. Baumgartner, G. Beaugrand, K. Drinkwater, J. M. Fromentin, S. R. Hare, G. Ottersen, R. I. Perry, C. Roy, C. D. van der Lingen, and F. Werner. Climate variability, fish, and fisheries. Journal of Climate, 19(20):5009-5030, 2006.

M. Leyton. The rise and making of the world's largest fishmeal producers: Historical overview and current trends in the chilean and peruvian fisheries industries. Technical report, IntraFishMedia,www.intrafish.com, 2001.

J. Lleonart, F. Maynou, L. Recasens, and R. Franquesa. A bioeconomic model for mediterranean fisheries, the hake off catalonia (western mediterranean) as a case study. Scientia Marina, pages 337-351, 2003.

D. Lluch-Belda, R. A. Schwartzlose, R. Serra, R. Parrish, T. Kawasaki, D. Hedgecock, and R. J. M. Crawford. Sardine and anchovy regime fluctuations of abundance in four regions of the world oceans: a workshop report. Fisheries Oceanography, 1(4):339-347, 1992.

S. Mardle and S. Pascoe. Modelling the effects of trade-offs between long and shortterm objectives in fisheries management. Journal of Environmental Management, 65(1):49-62, 2002.

E. Mente, G. Pierce, M. Santos, and C. Neofitou. Effect of feed and feeding in the culture of salmonids on the marine aquatic environment: a synthesis for european aquaculture. Aquaculture International, 14(5):499-522, 2006.

G. Merino, F. Maynou, and A. García-Olivares. Effort dynamics in a fisheries bioeconomic model: A vessel level approach through game theory. Scientia Marina, 71(3):0-0, 2007.

C. Mullon, P. Fréon, and P. Cury. The dynamics of collapse in world fisheries. Fish and Fisheries, 6(2):111-120, 2005. ISSN 1467-2960.

A. Nagurney. Network Economics. A variational inequality approach. Kluwer Academic Publishers, Dordrecht, 1993.

Nakicenovic. Special Report on Emissions Scenarios: A Special Report of Working Group III of the Intergovernmental Panel on Climate Change. Cambridge University Press, 2000. 
M. Nielsen. E.u. seafood markets - integration and demand. Technical report, SJFI, 1999.

S. Pascoe, J.E. Kirkley, D. Gréboval, and C.J Morrison-Paul. Measuring and assessing capacity in fisheries. issues and methods. FAO Fisheries Technical Paper 433, FAO, 1999.

D. Pauly. Anecdotes and the shifting baseline syndrome of fisheries. Trends Ecol. Evol., 10(10):430, 1995.

J. Pinnegar and G. Engelhard. The shifting baseline phenomenon: a global perspective. Reviews in Fish Biology and Fisheries, 18(1):1-16, 2008.

P. A. Samuelson. Spatial price equilibrium and linear programming. American Economic Review, 42:283-303, 1952.

J. N. Sanchirico and J.E. Wilen. Global marine fisheries resources: status and prospects. International Journal of Global Environmental Issues, 7(2-3):106-118, 2007.

J. R. Sargent. Fish oils and human diet. British Journal of Nutrition, 78(01): S5-S13, 2007.

M. B. Schaefer. Some aspects of dynamics of populations important to the management of commercial marine fisheries. Inter-Am. Trop. Tuna Comm. Bull., 1 (2):27-56, 1954.

R. A. Schwartzlose, J. Alheit, A. Bakun, and T. R. Baumgartner. Worldwide largescale fluctuations of sardine and anchovy populations. S. Afr. J. Mar. Sci., 21: 289-347, 1999.

V. L. Smith. On models of commercial fishing. The Journal of Political Economy, 77(2):181-189, 1969.

P.J. Sparre and R. Willman. Software for bio-economic analysis of fisheries. beam 4. analytical bio-economic simulation of space-structured multispecies and multifleet fisheries. In Computerized information series (Fisheries). FAO, 1993.

U. R. Sumaila, L. Teh, R. Watson, P. Tyedmers, and D. Pauly. Fuel price increase, subsidies, overcapacity, and resource sustainability. ICES J. Mar. Sci., 2008.

C. Ulrich, B. Le Gallic, M. R. Dunn, and D. Gascuel. A multi-species multi-fleet bioeconomic simulation model for the english channel artisanal fisheries. Fisheries Research, 58(3):379-401, 2002. doi: 10.1016/S0165-7836(01)00393-9.

J.M. Ward, J.E. Kirkley, R. Metzner, and S. Pascoe. Measuring and assessing capacity in fisheries. basic concepts and management options. FAO Fisheries Technical Paper 433, FAO, 1999.

D. L. Zhu and P. Marcotte. Modified descent methods for solving the monotone variational inequality problem. Operations Research Letters, 14(2):111-120, 1993. 
Appendix A. The System of SMAll Pelagic Fisheries AND Fishmeal or FISH OIL MARKETS

Fish is known to contain the highest level of natural proteins available in the world market, ranging from $64 \%$ (on dry matter) to more than 70\%, depending upon the species considered and the quality of the product. Dedication of small pelagic catches to fishmeal and fish oil production is related to the size of the resource available combined with the plant capacity available on-shore. Most of the resource processed into fishmeal and fish oil is caught within the 200-miles Economic Zone of the producing countries. In the last two decades the modernization of the fleets dedicated to small pelagic fish and improvements in handling and processing has increased the quality of landings, leading to a marked improvement in the conversion ratio.

Although very traditional for centuries in the northern countries of Europe, the fishmeal industry witnessed its real growth just after World War II, as it became the base of modern poultry feeding technique. Actually, the rapid growth of the poultry industry in the USA and, then, elsewhere in developed countries was a major booster to the fishmeal industry in the USA, based on Pacific sardines and Gulf menhaden, but also in Peru and Chile where it took over the more traditional guano industry (Leyton (2001)). Its spectacular and, to a certain extent, uncontrolled growth contributed to the major resource collapses in Peru in the early 70's, along the coast of California (Cisneros-Mata et al. (1995)), in Japan (Kawasaki (1993)). While the reasons for these collapses are debated, in the case of the Peruvian and Chilean anchovy fisheries it is now believed that a combinations of the effects of an El Nino event, a change of climatic regime and over-exploitation of an unregulated resource fishery caused the collapse (Alheit and Niquen (2004), Chavez et al. (2003)). Although the latter very lately recuperated, anchovy/sardine catches in Peru recovered quite well thanks to the high productivity of the Humboldt Current ecosystem combined with the very strict and responsive resource management policies developed by the Peruvian government during the 90's and implemented quite strictly in recent years.

Present fishmeal production and consumption trends are depicted in fig. 6; see also (Anderson (2003)). We note the importance of Peruvian and Chilean production, which represent more than $50 \%$ of the worldwide production. Other important producers are Iceland, Norway and Denmark where capelin, blue whiting, herring, sprat and sand eel constitute the main raw materials for the fishmeal industry.

The main producers of fish oil are the same as of fishmeal. Nevertheless, the importance of Japan and Iceland as fish oil producers must ne noted (fig. 6). International fish oil trade is less intense than for fishmeal, with many countries, e.g. Japan, Chile, USA, consuming most of their production.

Since 1990, aside from weather related production shortfalls (e.a. 2003), worldwide fishmeal production has been generally rather stable with a slight perception of a decline. However, this does not preclude the general conclusion that this stability lies on the efficiency of the fisheries management policies, mainly in Peru and Chile, to sustain catches (Sanchirico and Wilen (2007)).

Stakes: On the supply side. Worldwide catches of the species which are mainly dedicated to fishmeal and fish oil production are depicted in figure 7 . In recent 

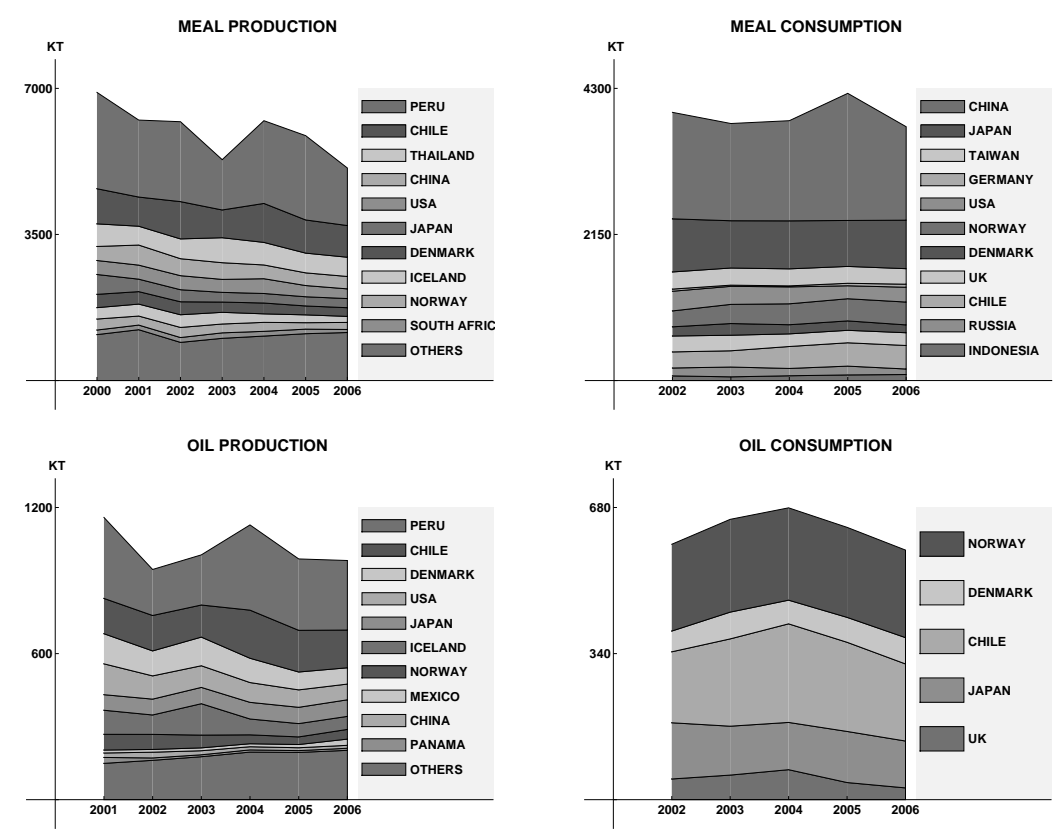

FiguRE 6. Top, left: Fish-meal production (from IFFO). Remind the transformation coefficient $\simeq 5$ between fish and fish-meal. Top, right: Fish-meal consumption (from IFFO). Differences with previous figure due to the category Other countries, not represented here. Bottom, left: Fish-oil production (from IFFO). Remind the transformation coefficient $\simeq 20$ between fish and fish-oil. Bottom, right : Fish-oil consumption (from IFFO).

years, they have reached a level of about $30 \mathrm{Mt}$, representing more than a third of the world's marine fish catch. A variability pattern appears with "pseudo-cycles" for most production systems, alternated high and low production levels on approximately decadal time scales (Schwartzlose et al. (1999), Fréon et al. (2008)). The amplitude of this variability is high with an order of magnitude 10 between low level and high level of production for almost all countries, species, and marine areas.

Some authors have observed synchronies between these pseudo-cycles of sardine and anchovy catches (Schwartzlose et al. (1999), Alheit and Niquen (2004)) : (1) sardine and anchovy populations tend to be out of synchrony in most areas e.g. if sardine is abundant, anchovy is not (Schwartzlose et al. (1999), Barange et al. (1999), Coetzee et al. (2008)) ; (2) peak and troughs in small pelagic are sometimes synchronic across systems, particularly in the Pacific (Lluch-Belda et al. (1992), Kawasaki (1993), Chavez et al. (2003), Hannesson et al. (2006)). However, the synchrony of these patterns has been questioned (Fréon et al. (2008)). As anchovies are mostly reduced to meal, while sardines are also canned for human consumption, the synchronies and associated substitution possibilities have important consequences for the fishmeal/oil production market.

Since the 1980s most of fisheries are regulated, mainly due to the institution of Exclusive Economic Zones. Practically all the major fishmeal industries are land 


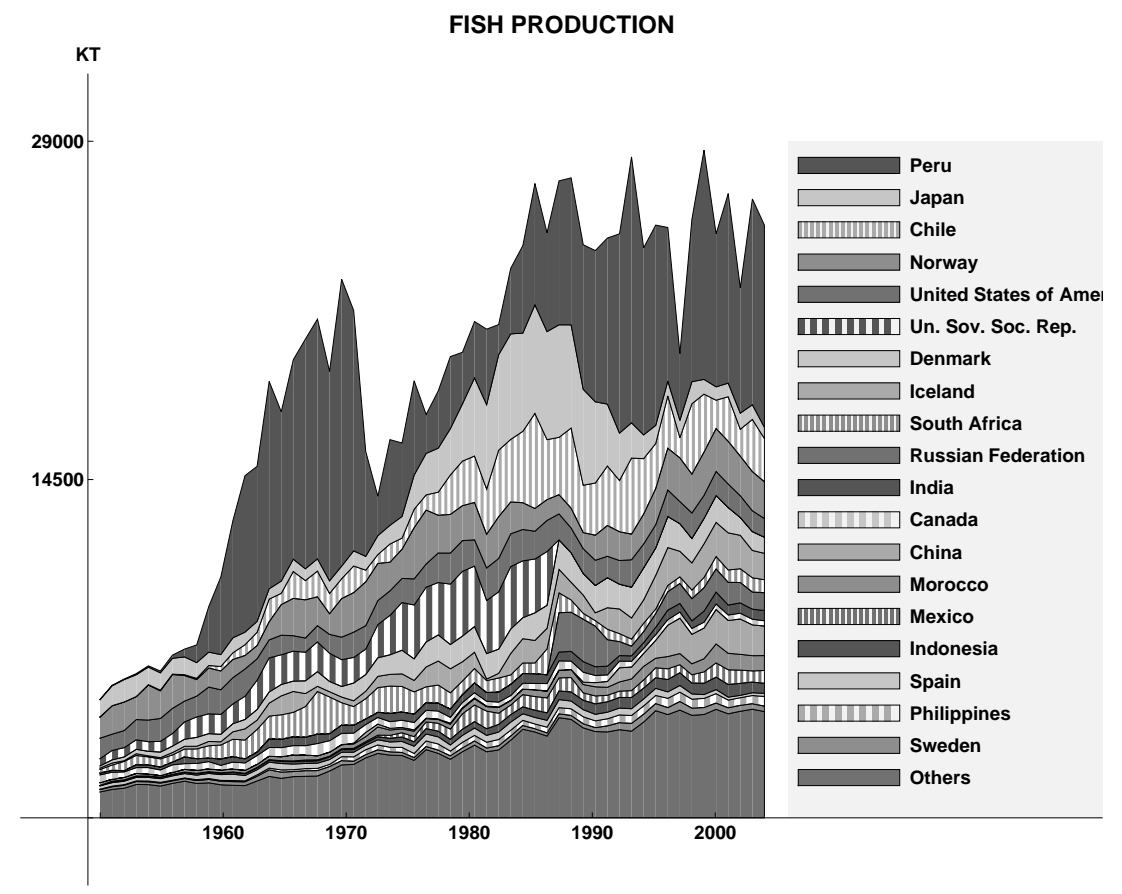

FIgure 7. Pelagic Production by countries(data issued from FAO Fishstat database). We have used the FAO category: Anchovies, Sardines, Herrings, plus Capelin, Sandeels and Blue Whiting.

based, i.e. they are supplied by raw materials generally caught within the 200 miles economic zone. Therefore all major producing countries do have the ability to tighten their control on the fisheries through an adequate regulatory system. In some instances, landings are controlled by a third party inspection service allowing their immediate reporting.

However, overcapacity is an important consideration. In Peru, for example, the recovering of the stock following the 1975 collapse led to an increase in both the number of fishing vessels and their mean carrying capacity, disconnected with biomass trends (Fréon et al. (2008)).

Overcapacity is due to both the lack or inadequacy of access regulations and to changes in the demand and supply conditions, which may generate idle capacity when fishing conditions are not profitable.

Stakes: On the demand side. There has been a long-term slowly growing trend in prices of fishmeal and fish oil in the last decade (fig. 8a and fig. 8b), with particularly strong increases in prices observed in the last two years. This sharp increase relates to the speculative behavior of buyers in anticipation of a major El Nino event at the end of 2006, which did not materialize. The structural drivers of growth in prices relate to a regular increase of demand mainly for aquaculture (Asche and Tveteras (2004), Hardy and Tacon (2002), Kristofersson and Anderson (2006), Mente et al. (2006), Deutsch et al. (2007)) and, concerning fishmeal, a limited substitution by other meals. 

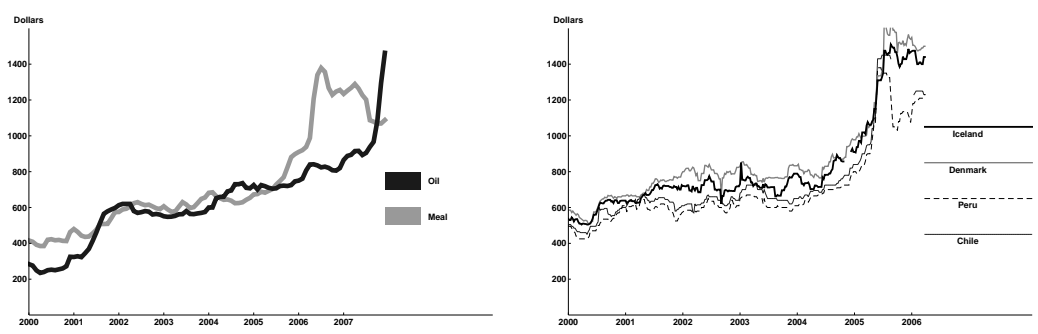

FiguRE 8. Fish-meal and fish-oil prices (from IFFO). Complement with more recent data showing a stabilization at a slightly lower level. Fish-meal prices in several countries(from IFFO). Remark the connections between these prices. This justifies the approach : there is a worldwide market; observed differences are due to different shipping costs and local features of demand markets.

Main substitute of fishmeal is soya meal. Substitution is the usual and only option for an end-user suddenly faced with a scarce commodity which price is rising accordingly. In the case of fishmeal, substitution is operating towards other sources of protein, mainly vegetal proteins such as soybean meal but also corngluten-feed, DDGS, the by-product of the ethanol industry when processed from corn. In the past decades, synthetic amino acids have also been used as partial substitutes to fishmeal although their use has been limited by their high price. More recently, the development of aquaculture, particularly of carnivorous fish species such as salmon has led to new opportunities for fishmeal usage, particularly for the higher qualities that the modernized fishmeal industry was able to supply. Thus, the substitution process is based on a complex balance between quality and/or specifications on one hand and price. In the 1980's and early 1990's, substitution was made only on a protein basis: a usual price ratio with soybean meal was in a range of 1.8 and 2.0, corresponding to the protein differential between fishmeal, around $65 \%$, and soybean meal, around $44 \%$. Starting in the late 90's/early 2000's, this price ratio rose progressively to another range of equilibrium between 2.8 and 3.1 , reflecting the additional advantages offered by fishmeal (nutritional values and oil content). In recent years, the ratio stabilized to a new range of 4.2/4.8 reflecting the disconnection between the two markets (Anderson (2003), Kristofersson and Anderson (2006)). Fishmeal is becoming a specialty ingredient market following its own market logic.

On the fish oil side, rape oil is frequently considered the best substitute to fish oil in fish feed. A new price ratio with rape oil has developed over time on account of the presence of omega-3 fatty acids in both oils (Sargent (2007)). However, the recent developments of alternative bio-energy sources such as diester have completely modified the price relationship between fish and rape oils. Actually, the combination of rising fish feed demand and rising rape oil prices has led to a significant rise of fish oil prices. But progressively, fish oil has also become an important nutrient in both animal and human nutrition programs due to its beneficial health attributes. Here again, it is now clear that this market is moving into a specialty product niche market where price competition is not any more dominant but also linked to the nutritional benefits it will bring to a feed ration. 
Appendix B. Solving variational inequalities. Proof of fundamental THEOREM

Theorem B.1. A shipment combination $\left(E_{s k}^{*}\right) \in \mathcal{H}$ is an equilibrium as defined in paragraph 2 if and only if it satisfies the variational inequality

$$
\sum_{s k} R_{s k}^{*}\left(E_{s k}-E_{s k}^{*}\right) \geq 0
$$

for all shipments $S=\left(E_{\text {sk }}\right) \in \mathcal{H}$.

Proof: Put $L_{s}^{M}=Y_{s}^{\max } / \tau_{m}$ and $L_{s}^{O}=Y_{s}^{\max } / \tau_{o}$.

(1) if part: suppose that $\left(E_{s k}^{*}\right) \in \mathcal{H}$ is an equilibrium; put $I=\left\{(s k) \mid E_{s k}^{*}>0\right\}$. We have:

$$
\begin{aligned}
\sum_{s k} R_{s k}^{*}\left(E_{s k}-E_{s k}^{*}\right)= & \sum_{(s k) \in I} R_{s k}^{*}\left(E_{s k}-E_{s k}^{*}\right)+\sum_{(s k) \notin I} R_{s k}^{*}\left(E_{s k}-E_{s k}^{*}\right) \\
= & -\sum_{(s k) \in I, k \in M} \lambda_{s}^{M}\left(E_{s k}-E_{s k}^{*}\right)-\sum_{(s k) \in I, k \in O} \lambda_{s}^{O}\left(E_{s k}-E_{s k}^{*}\right) \\
& +\sum_{(s k) \notin I} R_{s k}^{*} E_{s k} \\
\geq & -\sum_{(s k) \in I, k \in M} \lambda_{s}^{M}\left(E_{s k}-E_{s k}^{*}\right)-\sum_{(s k) \in I, k \in O} \lambda_{s}^{O}\left(E_{s k}-E_{s k}^{*}\right) \\
& -\sum_{(s k) \notin I, k \in M} \lambda_{s}^{M} E_{s k}-\sum_{(s k) \notin I, k \in O} \lambda_{s}^{O} E_{s k}
\end{aligned}
$$

because $E_{s k} \geq 0$ and $R_{s k}^{*} \geq-\lambda_{s}^{M}$ if $k \in M, R_{s k}^{*} \geq-\lambda_{s}^{O}$ if $k \in O$. Thus:

$$
\begin{aligned}
\sum_{s k} R_{s k}^{*}\left(E_{s k}-E_{s k}^{*}\right) & \geq \sum_{(s k) \in I, k \in M} \lambda_{s}^{M} E_{s k}^{*}-\sum_{(s k), k \in M} \lambda_{s}^{M} E_{s k}+\sum_{(s k) \in I, k \in O} \lambda_{s}^{O} E_{s k}^{*}-\sum_{(s k), k \in O} \lambda_{s}^{O} E_{s k} \\
& =\sum_{s} \lambda_{s}^{M} Q_{s}^{* M}-\sum_{(s k), k \in M} \lambda_{s}^{M} E_{s k}+\sum_{s} \lambda_{s}^{O} Q_{s}^{* O}-\sum_{(s k), k \in O} \lambda_{s}^{O} E_{s k}
\end{aligned}
$$

by definition of $I$. Thus:

$$
\begin{aligned}
\sum_{s k} R_{s k}^{*}\left(E_{s k}-E_{s k}^{*}\right) \geq & \sum_{s} \lambda_{s}^{M} Q_{s}^{* M}-\sum_{s} \lambda_{s}^{M} Q_{s}^{M}+\sum_{s} \lambda_{s}^{O} Q_{s}^{* O}-\sum_{s} \lambda_{s}^{O} Q_{s}^{O} \\
= & \sum_{s, Q_{s}^{* M}=L_{s}^{M}} \lambda_{s}^{M} Q_{s}^{* M}-\sum_{s, Q_{s}^{* M}=L_{s}^{M}} \lambda_{s}^{M} Q_{s}^{M} \\
& +\sum_{s, Q_{s}^{* O}=L_{s}^{O}} \lambda_{s}^{O} Q_{s}^{* O}-\sum_{s, Q_{s}^{* O}=L_{s}^{O}} \lambda_{s}^{O} Q_{s}^{O}
\end{aligned}
$$

because $\lambda_{s}^{M}=0$ if $Q_{s}^{* O}<L_{s}^{M}$ and $\lambda_{s}^{O}=0$ if $Q_{s}^{* O}<L_{s}^{M}$. Finally,

$$
\begin{aligned}
\sum_{s k} R_{s k}^{*}\left(E_{s k}-E_{s k}^{*}\right) & \geq \sum_{s, Q_{s}^{* m}=L_{s}^{M}} \lambda_{s}^{M}\left(L_{s}^{M}-Q_{s}^{M}\right)+\sum_{s, Q_{s}^{* o}=L_{s}^{O}} \lambda_{s}^{O}\left(L_{o}^{M}-Q_{s}^{O}\right) \\
& \geq 0
\end{aligned}
$$


because $\lambda_{s}^{M} \geq 0, \lambda_{s}^{O} \geq 0$ and $Q_{s}^{M} \leq L_{s}^{M}, Q_{s}^{O} \leq L_{s}^{O}$. This proves the variational inequality.

(2) only if part: suppose that $E^{*}=\left(E_{s k}^{*}\right) \in \mathcal{H}$ satisfies the variational inequality $\sum_{s k} R_{s k}^{*}\left(E_{s k}-E_{s k}^{*}\right) \geq 0$ for all shipments $\left(E_{s k}\right) \in \mathcal{H}$. For a given pair $s k$, we consider shipment defined by $E_{s^{\prime} k^{\prime}}=E_{s^{\prime} k^{\prime}}^{*}$ whenever $\left(s^{\prime} k^{\prime}\right) \neq(s k)$ and $E_{s k}=0$. It is clear that $E \in \mathcal{H}$. According to variational inequality: $R_{s k}^{*}\left(-E_{s k}^{*}\right) \geq 0$. Thus $E_{s k}^{*}>0 \Rightarrow R_{s k}^{*} \leq 0$. Let's now show that for two shipments $s k$ and $s l$ of the same product, for example fish-meal $(k \in M, l \in M)$, such that $E_{s k}^{*}>0$ and $E_{s l}^{*}>0$, we have $R_{s k}^{*}=R_{s l}^{*}$. We consider a state $S=\left(E_{s k}\right) \in \mathcal{H}$ such that $S_{s^{\prime} k^{\prime}}=E_{s^{\prime} k^{\prime}}^{*}$ whenever $\left(s^{\prime} k^{\prime}\right) \neq(s k),\left(s^{\prime} k^{\prime}\right) \neq(s l)$, and $E_{s k}=E_{s k}^{*}-\epsilon$, $S_{s l}=E_{s l}^{*}+\epsilon$. As $Q_{s}^{M}=Q_{s}^{* m}, S \in \mathcal{H}$. But variational inequality results in: $R_{s k}^{*}\left(E_{s k}-E_{s k}^{*}\right)+R_{s l}^{*}\left(S_{s l}-E_{s l}^{*}\right) \geq 0$. That is $\left(R_{s k}^{*}-R_{s l}^{*}\right) \epsilon \geq 0$. As we can take $\epsilon>0$ as well as $\epsilon<0$, we get $R_{s k}^{*}=R_{s l}^{*}$. We note $\lambda_{p}^{M}$ this common value. If $Q_{s}^{* M}<L_{s}^{M}$, for $m$, it is possible to consider a shipment $S \in \mathcal{H}$ defined by $S_{s^{\prime} k^{\prime}}=E_{s^{\prime} k^{\prime}}^{*}$ whenever $\left(s^{\prime} k^{\prime}\right) \neq(s k)$ and $E_{s k}>E_{s k}^{*}$. We get $R_{s k}^{*} \geq 0$. That is $\lambda_{s}^{M}=0$. 